\title{
Evaluation of Seismic Behaviors of Partially Deteriorated Reinforced Concrete Circular Columns Retrofitted with CFRP
}

\author{
Dongxu Hou, ${ }^{1}$ Jianyun Pan, ${ }^{2}$ Xinglang Fan, ${ }^{3}$ Zhimin Wu, ${ }^{1}$ and Prosper Marindiko ${ }^{1}$ \\ ${ }^{1}$ State Key Laboratory of Coastal and Offshore Engineering, Dalian University of Technology, Dalian 116024, China \\ ${ }^{2}$ Landscapes and Architecture College, Zhejiang Agricultural and Forestry University, Linian 311300, China \\ ${ }^{3}$ School of Civil Engineering and Architecture, Zhejiang University of Technology, Hangzhou 310014, China \\ Correspondence should be addressed to Dongxu Hou; dongxv666@126.com
}

Received 13 May 2014; Accepted 6 August 2014; Published 25 September 2014

Academic Editor: Alkiviadis Paipetis

Copyright (C) 2014 Dongxu Hou et al. This is an open access article distributed under the Creative Commons Attribution License, which permits unrestricted use, distribution, and reproduction in any medium, provided the original work is properly cited.

Deficiency of the concrete strength in some regions of reinforced concrete (RC) columns in practice may weaken the seismic behaviors of columns. Its effects on RC columns should be well understood. This paper aims to investigate the influences of deteriorated segment on the seismic behaviors of partially deteriorated RC columns and attempts to recover the seismic behaviors of partially deteriorated columns with Carbon Fiber Reinforced Polymer (CFRP) composites. A finite element analysis was carried out to simulate the seismic behaviors of CFRP-confined partially deteriorated RC columns. The numerical results were verified by the laboratory tests of six specimens. Based on the finite element results, the failure location of partially deteriorated columns in an earthquake was predicted, and the effectiveness of CFRP retrofitted on partially deteriorated columns was evaluated.

\section{Introduction}

Many factors such as freezing, corrosion, and insufficient vibration during construction may result in the partial deterioration of RC columns, which might lead to premature failure of columns in earthquakes. It is, thus, necessary to take some retrofitting measures on recovering the seismic behaviors of partially deteriorated RC columns. Wrapping Carbon Fiber Reinforced Polymers (CFRP) sheets is a good choice to retrofit $\mathrm{RC}$ columns in structural engineering. The effectiveness of CFRP in improving seismic behaviors of RC columns has been widely recognized. Promis et al. $[1,2]$ and Colomb et al. [3] focused on the seismic behaviors of RC short columns retrofitted with CFRP composites. Results showed that the seismic behaviors of RC short columns can be improved significantly by wrapped CFRP sheets. Ye et al. [4] verified the strengthening effectiveness through seismic experiments on retrofitted short columns and proposed a method to calculate the bearing capacities of strengthened columns. Shamim and Grace [5], Sheikh and Bayrak [6], and Iacobucci et al. [7] studied the seismic behaviors of CFRP retrofitted RC columns with different shape sections.
The conclusions showed that the retrofitting effect of CFRP not only depends on the axial load of confined column and the amount of CFRP, but also relates to the inner reinforcements.

Most of the studies mentioned above mainly focused on CFRP retrofitting intact RC columns, and few researchers related to the partially deteriorated RC columns. Wei et al. [810] examined the axial and eccentric compressive behaviors of CFRP retrofitting partially deteriorated RC columns. The results of the studies indicated that the wrapping CFRP is feasible to recover the axial and eccentric compressive behaviors of partially deteriorated columns. However, in Wei et al's study, the CFRP effectiveness of recovering the seismic behaviors of partially deteriorated columns has not been investigated. In addition, finite element analysis is needed to simulate the behaviors of partially deteriorated RC columns. Therefore, there exists a gap in studying the seismic retrofitting partially deteriorated RC column with CFRP, by either numerical or experimental method.

This paper aims to investigate the seismic performances of partially deteriorated RC columns and to evaluate the effectiveness of wrapped CFRP sheet. In this investigation, 
TABLE 1: Details of specimens in FEA.

\begin{tabular}{lccccccc}
\hline Specimen & $\begin{array}{c}D \\
(\mathrm{~mm})\end{array}$ & $\begin{array}{c}L \\
(\mathrm{~mm})\end{array}$ & $\begin{array}{c}R \\
(\mathrm{~mm})\end{array}$ & $\begin{array}{c}f_{\text {in }} \\
(\mathrm{MPa})\end{array}$ & $\begin{array}{c}f_{w} \\
(\mathrm{MPa})\end{array}$ & $\begin{array}{c}t_{\mathrm{crrp}} \\
(\mathrm{mm})\end{array}$ \\
\hline DB50 & 240 & 1300 & - & 52 & - & 22 & 0.1 \\
BR200 & 240 & 1300 & $0-250$ & 52 & 31 & 0.1 & 0. \\
BR300 & 240 & 1300 & $0-250$ & 52 & 31 & 0.1 & 0.1 \\
BR301 & 240 & 1300 & $0-250$ & 52 & 31 & 0.1 & 0.167 \\
BR302 & 240 & 1300 & $0-250$ & 52 & 22 & 0.1 & 0.334 \\
BR203 & 240 & 1300 & $0-250$ & 52 & 0.501 \\
\hline
\end{tabular}

the finite element analysis of the seismic behaviors of partially deteriorated RC columns retrofitted with CFRP was carried out using commercial software ABAQUS and verified by the laboratory tests of six specimens. Based on the calibrated finite element model, the failure location of deteriorated column in an earthquake was predicted, and the applied scope of CFRP on retrofitting partially deteriorated columns was discussed. The proposed method can be used for the risk assessment of partially deteriorated segment and making retrofitting scheme of CFRP in practice.

\section{Finite Element Modelling}

2.1. Modeling of Specimens. Finite element analysis was conducted with ABAQUS/Standard module [11]. The simulated specimens include one control column with intact strength $f_{\text {in }}$, two partially deteriorated columns with different deteriorated strength $f_{w}$, and three corresponding deteriorated columns retrofitted with different thickness CFRP $t_{\text {cfrp }}$. The height $L$, diameter $D$, and axial load ratio $N /\left(f_{\text {in }} A\right)$ of the specimens were identical. A $250 \mathrm{~mm}$ long deteriorated segment was designed at the column foot. The details of the numerical models are showed in Table 1 and Figure 1 . The deteriorated concrete was just simulated by low strength concrete in this research. The method of simulating deteriorated concrete with low strength concrete is just effective in the research aims to study the influence of concrete strength on the behaviours of substandard concrete.

2.2. Boundary Conditions and Load Application. Each column was cast into a concrete stub, and the bottom surface of the stub was restrained from movement in all directions, as shown in Figure 1. Displacement of the stub in the $x$ direction was also restrained to eliminate the effect of stub deformation on displacement. The top and lateral loading plates were fixed on the top of columns to prevent local crashing of concrete. Constant vertical and circular horizontal load was applied on two reference points coupled to the top and lateral loading plates, respectively. The slippage between reinforcement and concrete was neglected.

2.3. Element Type and Mesh. An eight-node solid element with reduced integration (C3D8R) was applied for modeling the concrete, loading plates, and rigid bases, and the longitudinal and transverse reinforcements were simulated by truss element (T3D2). The structured technique was used for

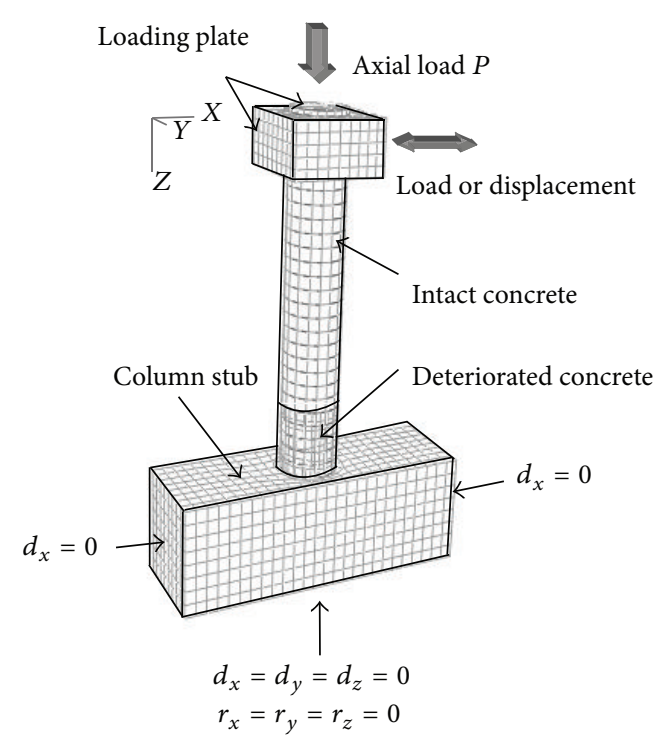

FIGURE 1: Finite element model of specimen.

meshing. The grid size of concrete was selected as $50 \mathrm{~mm}$, which is larger than the maximum dimension of coarse aggregate of concrete $20 \mathrm{~mm}$, to eliminate the inhomogeneity of concrete. The steel bar and CFRP sheets have the common grid size as concrete.

\subsection{Modeling of Materials}

2.4.1. Constitutive Model of Concrete. The damaged plasticity concrete model defined in ABAQUS/Standard was adopted in the analysis. This model is an isotropic plasticity model that resembles the Drucker-Prager model in terms of the compressive behaviors of concrete. The constitutive relationship under the multiaxial stress state is derived based on the nonassociated flow rule, where the Drucker-Prager hyperbolic flow potential function $G$ is used [12]:

$$
G=\sqrt{\left(e \sigma_{t 0} \tan \psi\right)^{2}+\bar{q}^{2}}-\bar{p} \tan \psi
$$

where $\psi$ is the dilation angle, $\sigma_{t 0}$ is the tensile strength, $\bar{q}$ is the Mises equivalent effective stress defined in terms of the effective stress tensor, $\bar{p}$ is the effective hydrostatic pressure, and $e$ is the eccentricity parameter. 


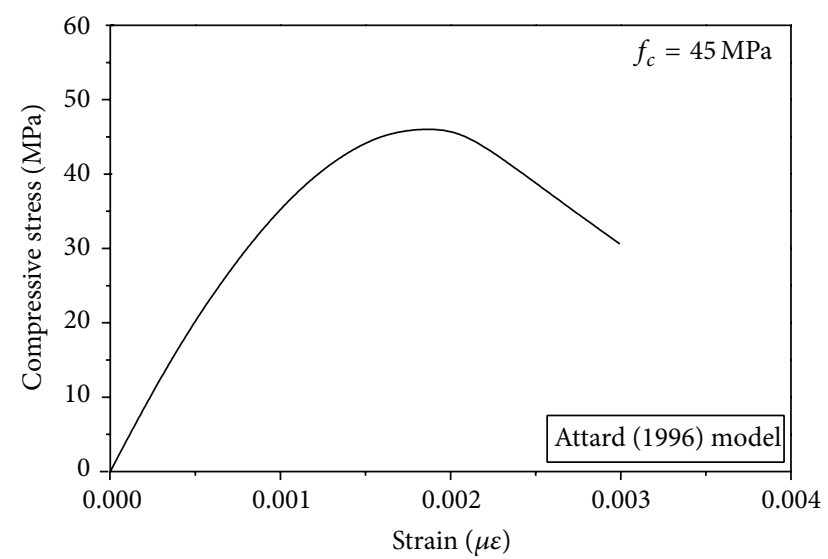

FIgURE 2: Compressive model of concrete.

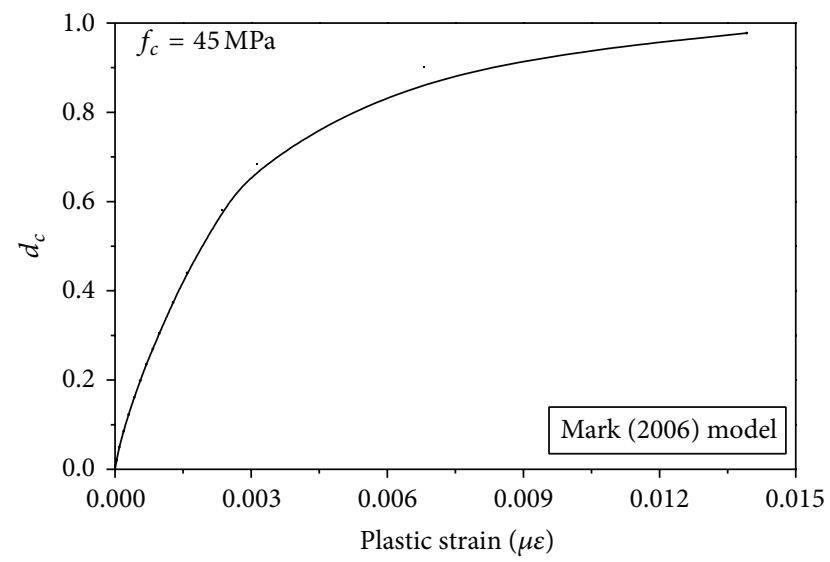

FIgURE 3: Compressive damage model of concrete.

The yield function was developed by Lublinear et al. [13] and modified by Lee and Fenves [14]. The failure surface is controlled by the compressive variable and tensile variable [15]. The unaxial stress-strain relationship of compressive and tension behaviors is required. Model of Attard and Setunge [16] was divided into two parabolic curves by the peak point and adopted in this research for its suitable serviceable range as shown in Figure 2. The strain of peak point of concrete $\varepsilon_{c}$ is calculated by means of axial compressive strength $f_{c}$, $\varepsilon_{c}=4.26 f_{c} /\left(E_{c} f_{c}^{0.5}\right)$. The elastic modulus $E_{c}$ is equal to $57000 f_{c}^{1 / 2}$ psi according to ACI-318 [17]. The stress and strain of ultimate point are determined by the following formulas: $f_{i c}=\left(1.41-0.17 \ln \left(f_{c}\right)\right) f_{c}$ and $\varepsilon_{i c}=\left(2.5-0.3 \ln \left(f_{c}\right)\right) \varepsilon_{c}$. The model of Mark and Birtel [18] was selected as the compressive damage model, which is presented by means of damage ratio variation $d_{c i}$ during transverse loading, as shown in Figures 3 and 4 .

The tension strength of concrete $f_{t}$ is calculated by $0.3 f_{c}^{2 / 3}$ [19]. Gopalaratnam and Shah's model [20], a relationship between tension stress and crack opening displacement, was used to describe the tensile behavior of concrete as shown in Figure 5. The ultimate crack opening displacement was considered as $160 \mu \mathrm{m}$.

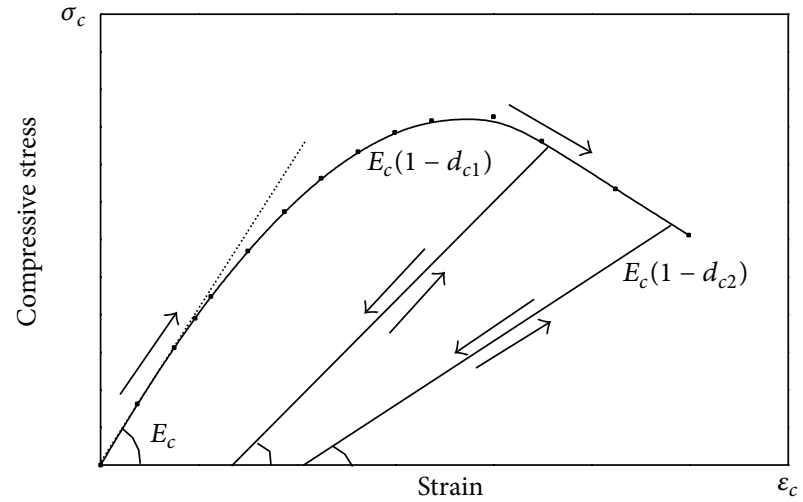

FIGURE 4: Compressive damage index of concrete.

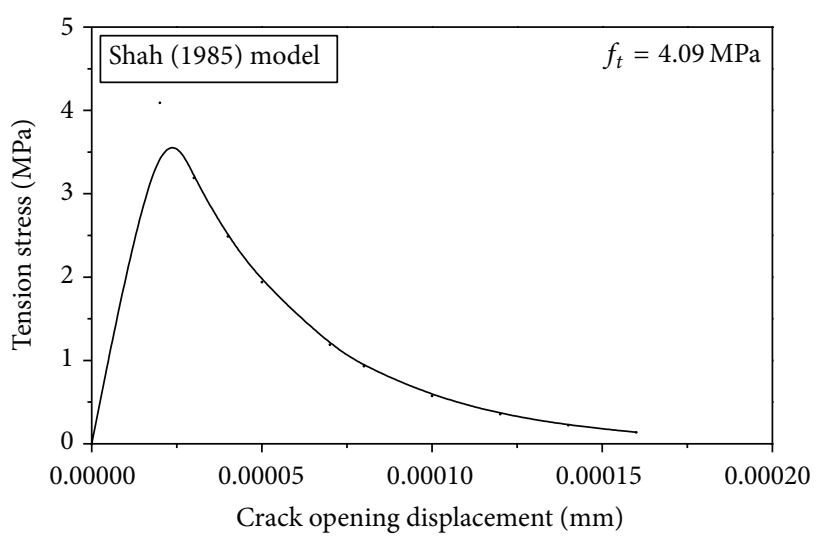

FIGURE 5: Tension model of concrete.

2.4.2. Constitutive Model for Steel Bar. In the numerical model, deformed steel bars were adopted as longitudinal reinforcements, and plain bars were used as transverse reinforcements. As shown in Figure 6, reinforced bars were assumed as idealized elastic-plastic material, and the required yield strength and elastic modulus $E_{s}$ in idealized stressstrain curve of steel bar were obtained from coupon test. The yield stress of longitudinal and transverse reinforcement is $360 \mathrm{MPa}$ and $290 \mathrm{MPa}$, respectively. The finite element model of reinforcement cage was shown in Figure 7. Mises stress was used to present the state and stress of steel bar in any moment.

2.4.3. Constitutive Model for CFRP. CFRP sheet can be modelled as an orthotropic elastic material. The elastic modulus in the tensile direction $E_{\text {cfrp }}$, Poisson's ratio $v_{\text {cfrp }}$, and ultimate stress $f_{\text {cfrp }}$ were measured as $235 \mathrm{GPa}, 0.25$, and $3400 \mathrm{MPa}$, respectively. According to Teng et al's result [21], the actual tension rupture strain of CFRP $\varepsilon_{h \text {,rup }}=0.586 \varepsilon_{\text {cfrp }}$, where $\varepsilon_{\text {cfrp }}$ is the tension strain obtained from coupon test. The reduced integration quadrilateral membrane element with four nodes (M3D4R) was selected to simulate the behavior of CFRP sheet. The slippage between CFRP and concrete was ignored. Figure 8 is the finite element model of confined CFRP, and 
TABLE 2: Experimental and FEA results of specimens.

\begin{tabular}{|c|c|c|c|}
\hline Specimen & $\begin{array}{l}N_{\exp } \\
(\mathrm{kN})\end{array}$ & $\begin{array}{r}N_{\text {FEM }} \\
(\mathrm{kN})\end{array}$ & $\frac{\left|N_{\exp }-N_{\mathrm{FEM}}\right| \times 100 \%}{N_{\exp }}$ \\
\hline DB50 & 42.6 & 39.2 & $7.9 \%$ \\
\hline BR200 & 29.8 & 30.1 & $10.0 \%$ \\
\hline BR203 & 39.1 & 39.8 & $1.8 \%$ \\
\hline BR300 & 35.6 & 34.4 & $3.4 \%$ \\
\hline BR301 & 38.9 & 37.2 & $4.3 \%$ \\
\hline BR302 & 41.0 & 41.6 & $1.5 \%$ \\
\hline
\end{tabular}

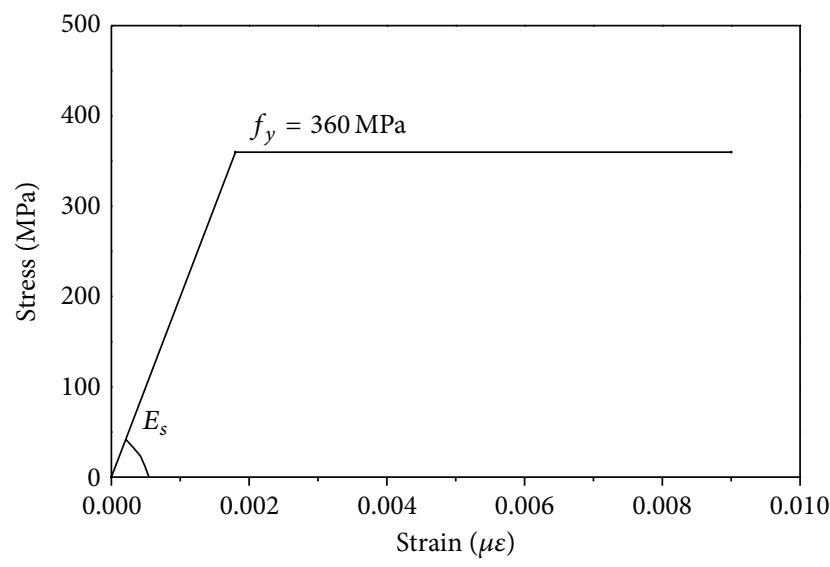

FIGURE 6: Idealized elastic-plastic model of reinforcement.

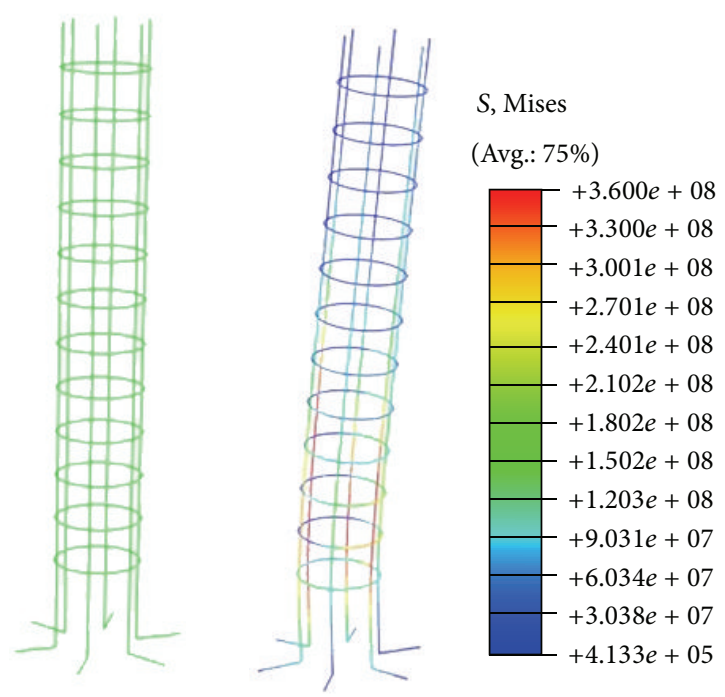

FiguRE 7: Finite element model of reinforcements.

the rupture of tensile fiber is defined as the failure moment of retrofitted specimens, which is measured by the logarithm strain (LE) of CFRP.
2.5. Results of Finite Element Analysis. Based on the finite element model mentioned above, the hysteretic loops of six specimens were predicted. The details of numerical model were shown in Table 1 and Figure 9. The numerical results were compared in Figures 10 and 11, where specimen names suffixed with the letter " $f$ " in the figures present the numerical specimen names. Figure 10 indicates that when the deteriorated segment is located at the foot of the column, the seismic behaviors are greatly reduced. The hysteretic loops of retrofitted columns and control column, shown in Figure 11, present the retrofitting effects of wrapped CFRP. It is obviously shown that the seismic behaviors of deteriorated column with deteriorated strength $22 \mathrm{MPa}$ and $31 \mathrm{MPa}$ can be basically recovered by the effect of 3 layers and 2 layers CFRP wrapping, respectively.

\section{Experimental Verifications}

3.1. Experimental Instruments. The finite element model described above was validated against the laboratory test results. A total of six specimens corresponding to the numerical specimens were tested. As shown in Figure 12, each column was placed in an existing frame with a $200 \mathrm{t}$ hydraulic actuator. The column stubs were fastened to the rigid floor with four high-strength rods to prevent slipping and overturning under large lateral loads. The actuator with a $200 \mathrm{t}$ load cell was mounted vertically onto the frame to apply the vertical axial load. Another two $30 \mathrm{t}$ horizontal hydraulic actuators with load cells were used to apply lateral reversal load. All instrumentations were connected to IMC data acquisition system for data selection. Under a sustained constant axial load, the horizontal loading was applied in a load-controlled and displacement-controlled manner before and after the stress in longitudinal bars reaches the yield strength, respectively.

3.2. Verifications of Proposed Finite Element Model. The experimental and FEA results are shown in Figures 13(a)13(f) and Table 2, where $N_{\text {exp }}$ and $N_{\text {FEM }}$ are the experimental and numerical bearing capacity of specimens, respectively. Owing to the ignoring of slippage between concrete and reinforcement bars, the displacements of the partially deteriorated columns in FEA are slightly smaller than the test results. 

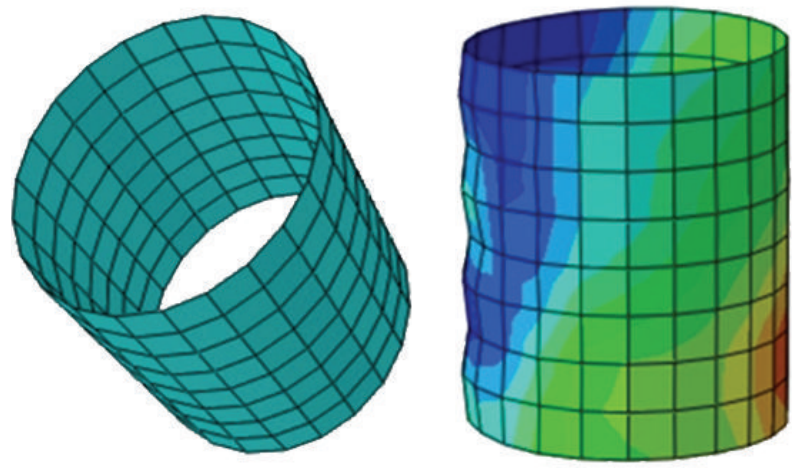

LE, LE22

(Avg.: $75 \%)$

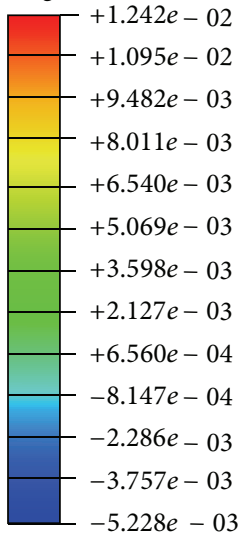

FIgURE 8: Finite element model of CFRP.
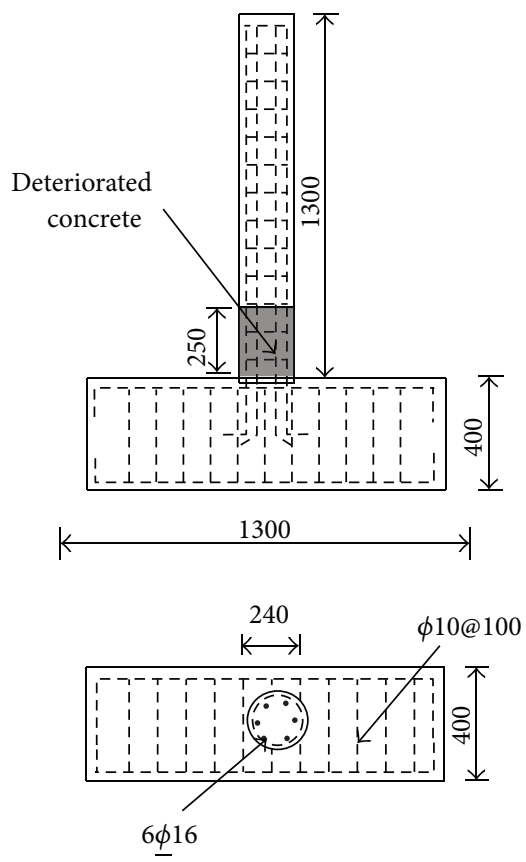

Figure 9: Details of specimen.

Figure 14 shows the experimental and numerical predicted failure state of specimens. It is clearly seen from Figures 14(a)-14(f) that the predicted failure state is similar to the experimental specimens, which means the proposed finite element model can not only predict the hysteretic curves of specimens accurately, but also simulate the failure state effectively.

The experimental hysteretic loops shown in Figures 15 and 16 present similar regularity to the ones obtained from finite element analysis in Figures 10 and 11. It is clearly visible that the experimental results have a good agreement with the FEA results, which means that the proposed finite element model is valid to predict the seismic behaviors of partially deteriorated columns and retrofitting effect of wrapped CFRP.

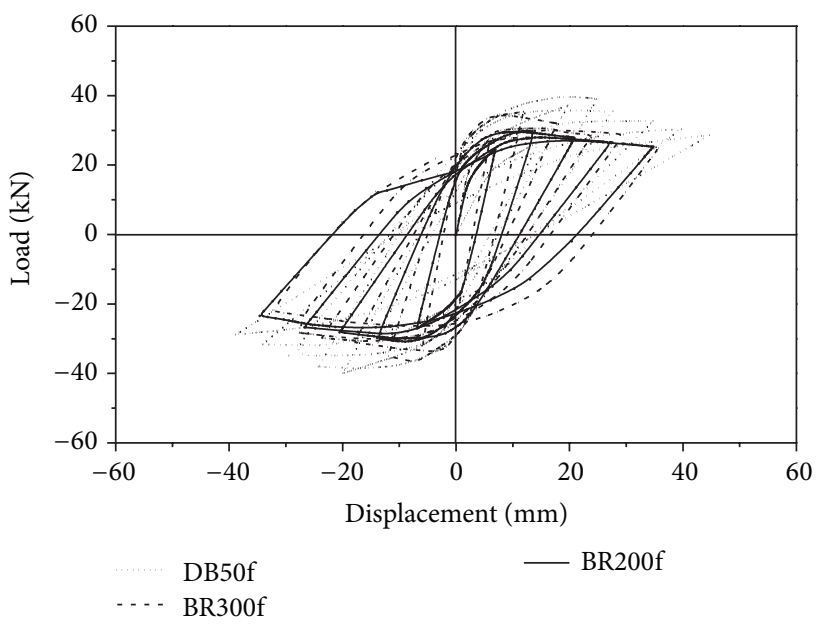

Figure 10: Numerical hysteretic loops of partially deteriorated columns and control column.

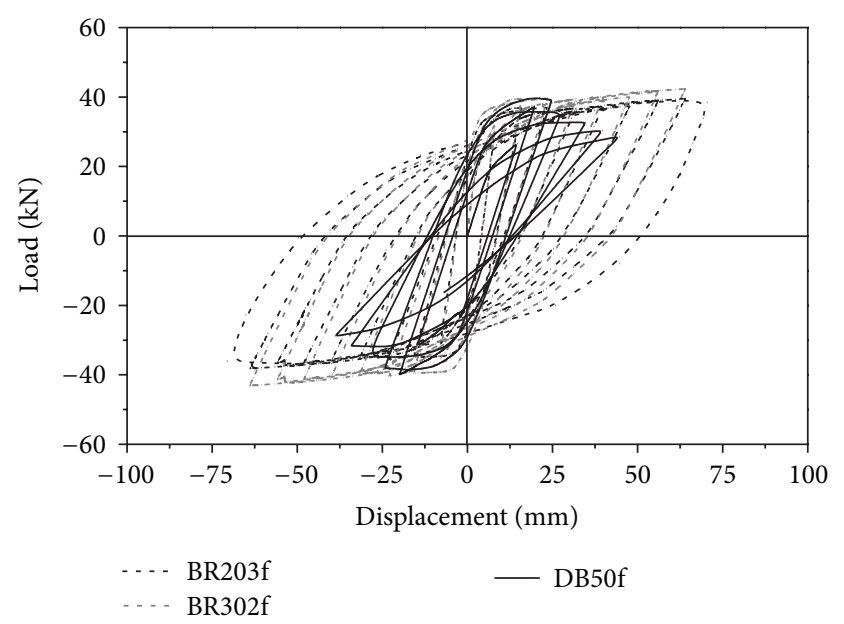

FIGURE 11: Numerical hysteretic loops of retrofitted deteriorated columns and control column. 


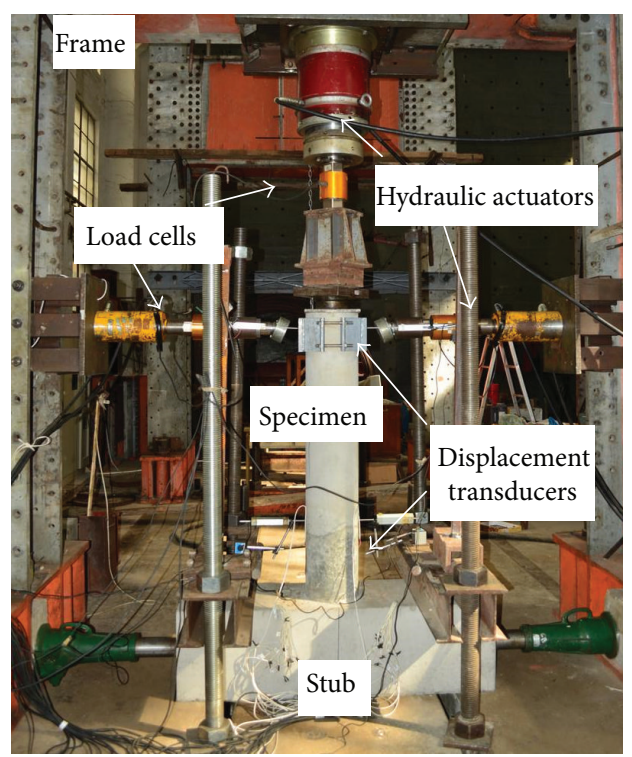

FIGURE 12: Experimental setup.

\section{Failure Location on Partially Deteriorated Columns}

Both the experimental and numerical results show that the seismic behaviors of the deteriorated columns were weakened seriously by the partially deteriorated segment located at the foot of the columns. However, the influence of changing location of the deteriorated segment on the seismic behaviors of the whole column is still unknown. The above study indicates that the finite element model can accurately predict the seismic behaviors and failure locations of partially deteriorated columns. The partially deteriorated columns with different deteriorated segment height will be examined in the following sections by means of finite element analysis.

4.1. Deteriorated Segment Height. Variation of the height of the deteriorated segment above the base of the column was studied first. Three partially deteriorated columns, with the same deteriorated strength and axial load ratio, were examined. The heights of the deteriorated segments above the base of three columns varied from 0.23 to 0.38 times the height of the columns. Figure 17(a) shows that the failure of column, judged by the plastic strain on concrete, appears on the deteriorated segment. With the ascendance of the deteriorated segment location, the failure field location turned from deteriorated segment to the foot of columns gradually, as shown in Figure 17(c). It is deduced that the failure of each partially deteriorated column has a critical state, when the deteriorated segment and the foot of the column fail simultaneously as in Figure 17(b). The location of deteriorated segment above the foot of the column $H$ at the critical state is defined as critical deteriorated height $H_{l j}$. In practice, when $H$ is higher than $H_{l j}$, the failure of deteriorated columns occurs on the foot of the column rather than the deteriorated segment, there is no need to retrofit column, and, inversely, the partially deteriorated column needs to strengthen. $H_{l j}$ is therefore vital for partially deteriorated column as it indicates the necessity of strengthening partially deteriorated columns.

4.2. Axial Load Ratio. The influence of axial load ratio on the critical deteriorated segment height was also investigated. Three columns with different axial load ratios $\lambda$ ranging from 0.2 to 0.6 were examined as shown in Figure 18. When the axial load ratio is equal to 0.2 , the plastic hinge zone of specimen failed firstly, as shown in Figure 18(a). With the increment of axial load ratio, the balance state is destructive. When the axial load ratio reached 0.6 as shown in Figure 18(c), the failure appears on the deteriorated segment entirely. Figure 18(b) presents a critical state of partially deteriorated column with axial load ratio $\lambda_{l j}$ equal to 0.4 . Thus, the critical deteriorated height of partially deteriorated column is sensitive to the axial load ratio.

4.3. Slenderness Ratio. The influence of slenderness ratio on critical deteriorated height was investigated, and the critical state of columns with different slenderness ratio was shown in Figure 19. It is clearly shown in Figures 19(a)19(c) that the absolute distance from column base to the critical deteriorated concrete segment turns larger with the increasing of slenderness ratio of columns, whereas the relative distance of critical deteriorated concrete is almost the same, which means the changing of slenderness ratio of column has little influence on the critical deteriorated segment height of partially deteriorated column.

4.4. Deteriorated Ratio. Deteriorated ratio $R_{k}$ is defined as the ratio of the strength difference between the intact concrete strength and the deteriorated concrete strength to the strength of intact concrete $\left(R_{k}=\left(f_{\text {in }}-f_{w}\right) / f_{\text {in }}\right)$. Critical deteriorated segment heights of seven partially deteriorated columns, with different deteriorated ratios, were studied finally. The deteriorated ratios varied from 0.1 to 0.7 as shown in Figure 20. It is clearly visible that the critical segment deteriorated height moved up with the increment of deteriorated ratio, which means the critical deteriorated segment height has a close relation to the deteriorated ratio and location of deteriorated segments.

\subsection{Determination of Critical Deteriorated Segment Height.} In the following section, the critical deteriorated segment height $H_{l j}$ of 42 partially deteriorated columns with different deteriorated ratios, under different axial load ratios, was studied. The FEA results of critical failure locations are shown in Table 3 and Figure 21, which shows that the deteriorated ratio and relative height of deteriorated segment have a linear relationship under a certain axial load ratio, and the slope of the lines is related to the axial load ratio. Based on the analysis, a formula to determine the critical deteriorated segment locations of partially deteriorated columns was developed:

$$
\frac{H_{l j}}{L}=(0.2583 \lambda+0.5324) R_{k}+0.0238 \lambda-0.0118,
$$




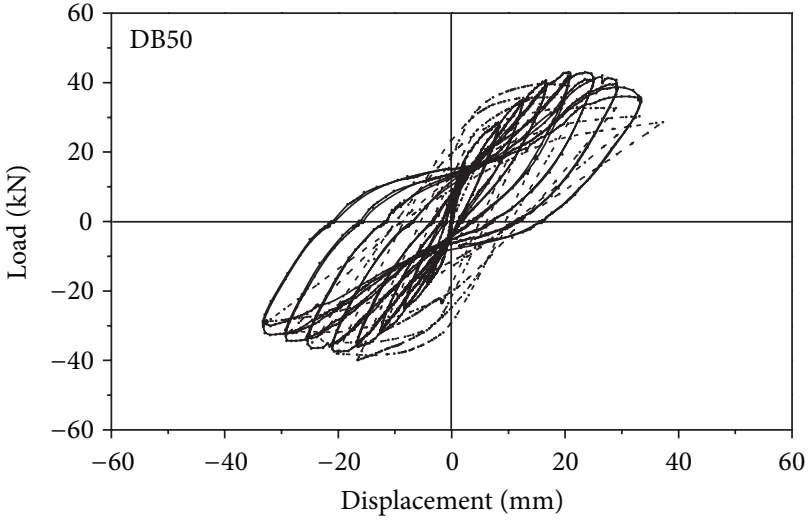

(a) DB50

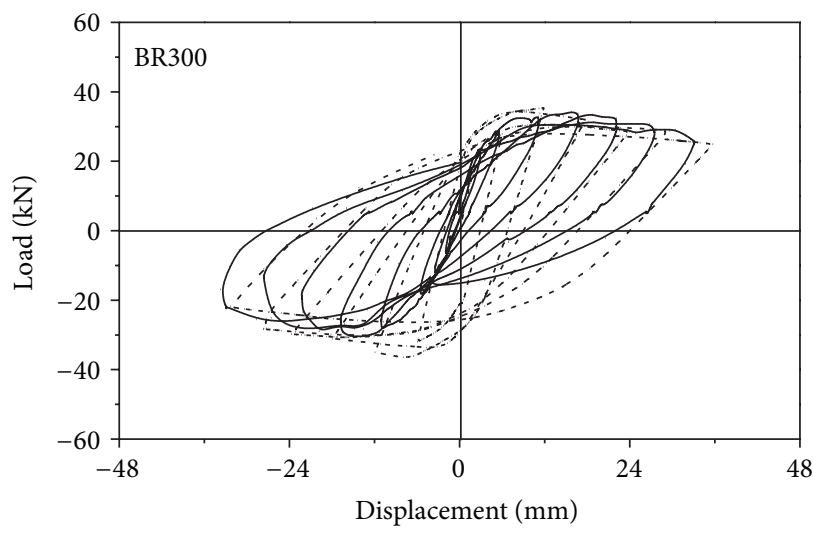

(c) BR300

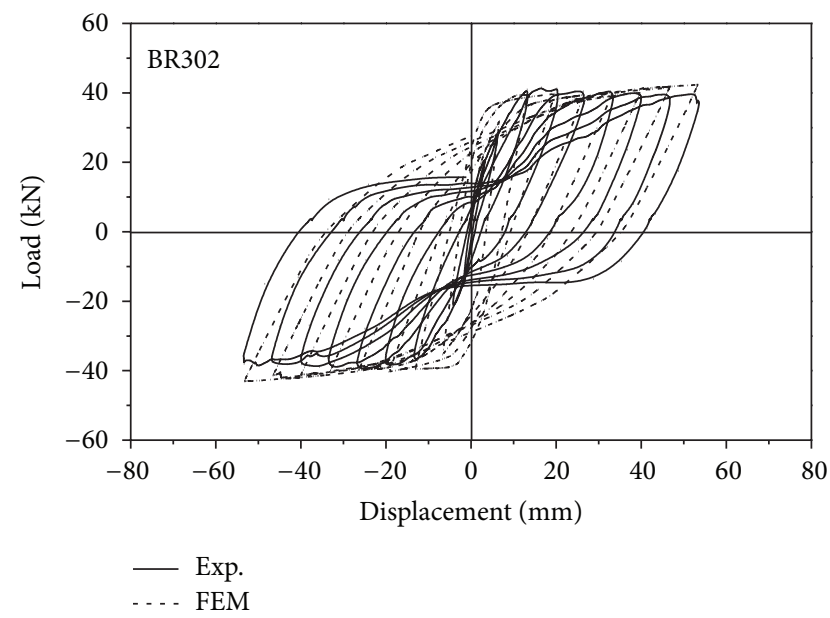

(e) BR302

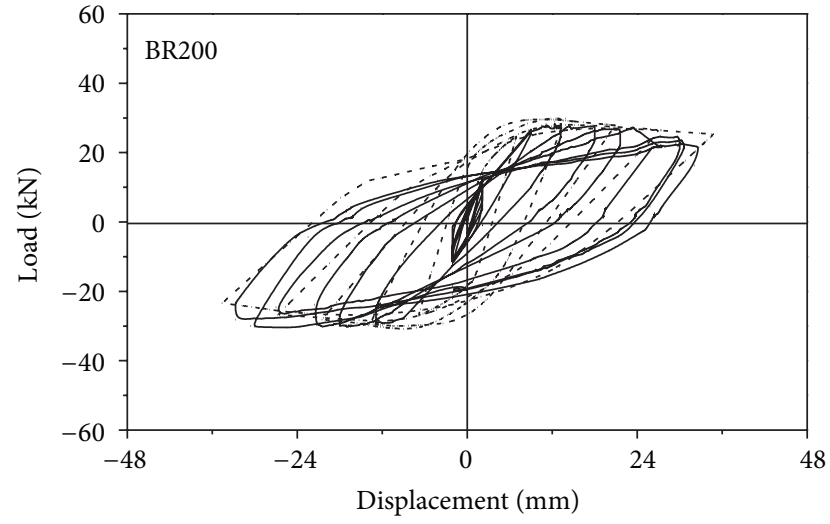

(b) BR200

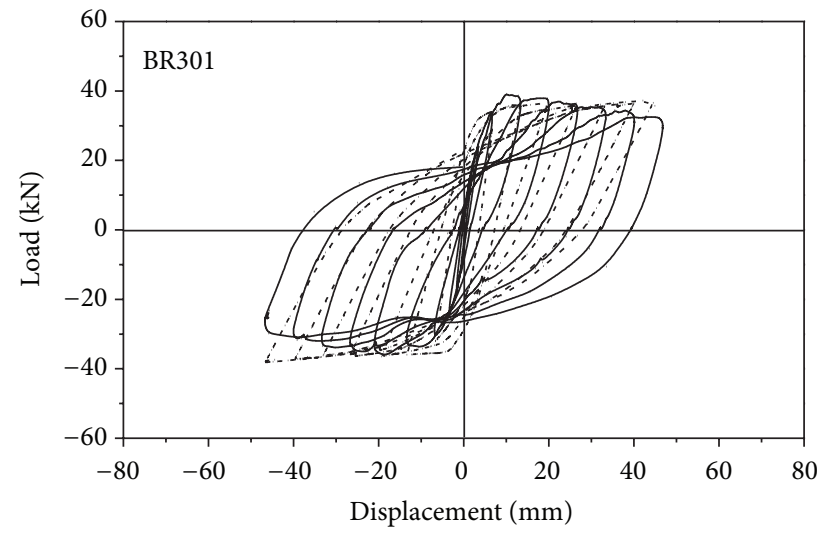

(d) BR301

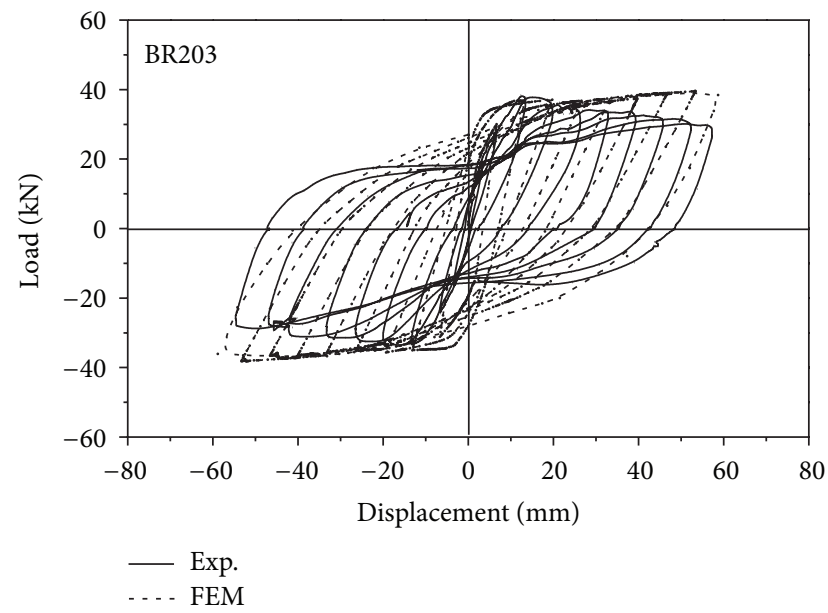

(f) BR203

FIGURE 13: Experimental and numerical hysteretic loops of specimens.

where $\lambda$ is the axial load ratio of column, $L$ is the length of column, and $A$ is the section area of column. All of the parameters needed in the formula are measurable in practice, and the critical deteriorated height of partially deteriorated columns $H_{l j}$ can be calculated easily. If the location of deteriorated segment is lower than $H_{l j}$, the column should be strengthened to prevent the premature failure in an earthquake. This method is effective just for the columns with $R_{k}$ lower than 0.7 and $\lambda$ lower than 0.6 .

\section{Validity of Reinforcement with CFRP}

5.1. Valid CFRP Thickness. The hysteretic loops of partially deteriorated column BR200 and its retrofitted specimens 

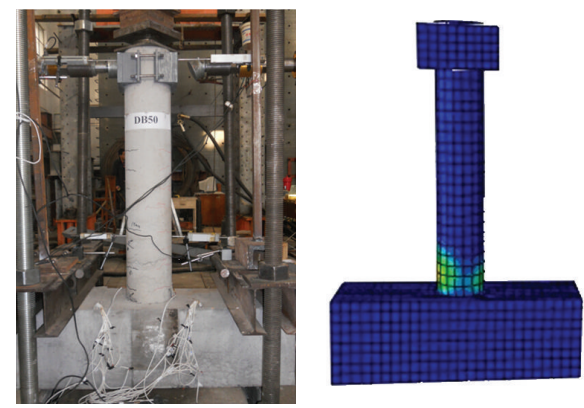

(a) DB50
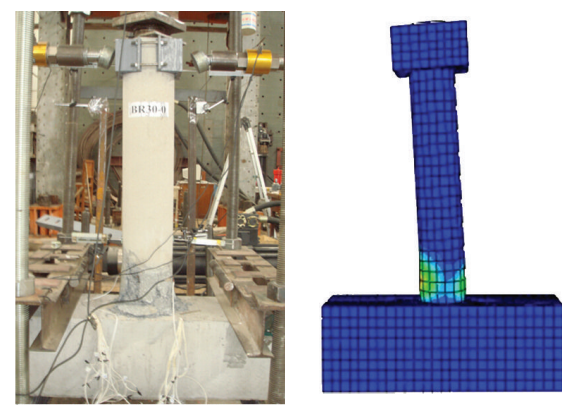

(c) BR300
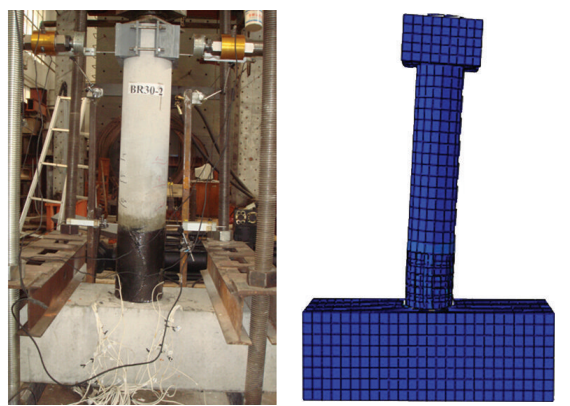

(e) BR302
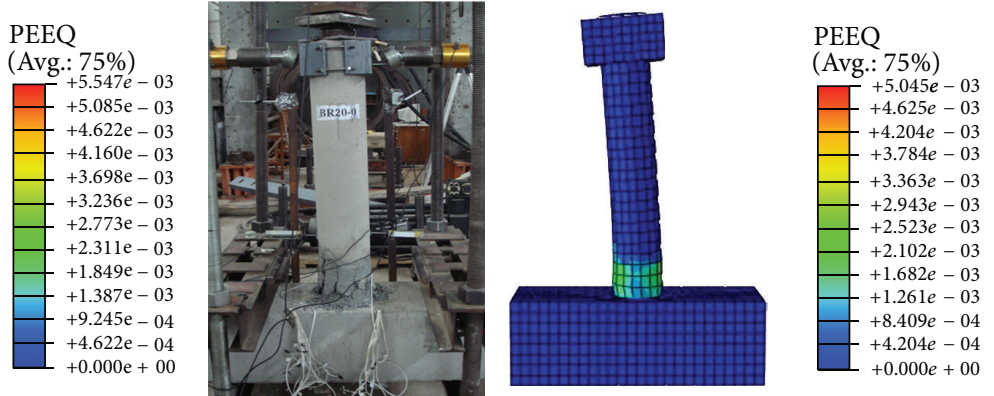

(b) BR200
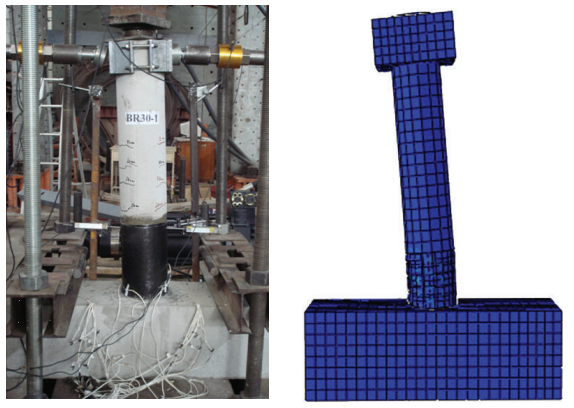

PEEQ (Avg.: 75\%)

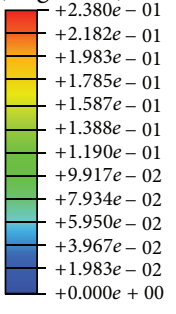

(d) BR301

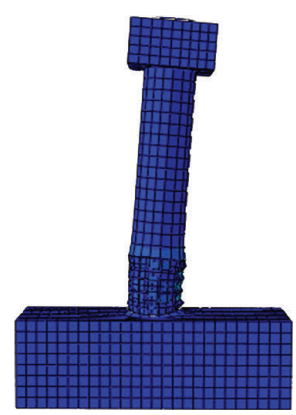

PEEQ

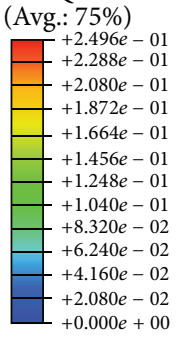

(f) BR203

FIGURE 14: Experimental and FEA predicted failure state of specimens.

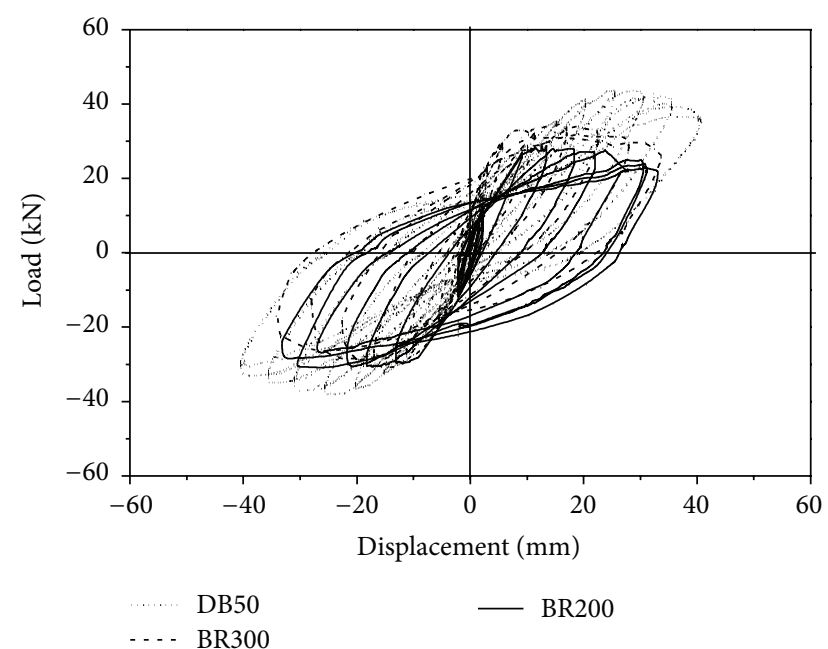

FIgURE 15: Experimental hysteretic loops of the partially deteriorated columns and the control column.

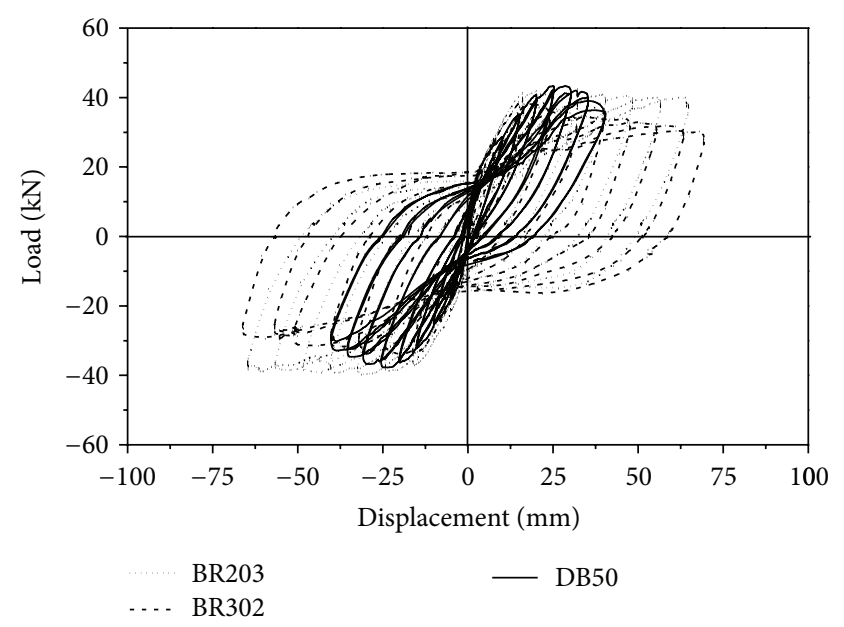

FIGURE 16: Experimental hysteretic loops of retrofitted deteriorated columns and the control column. 


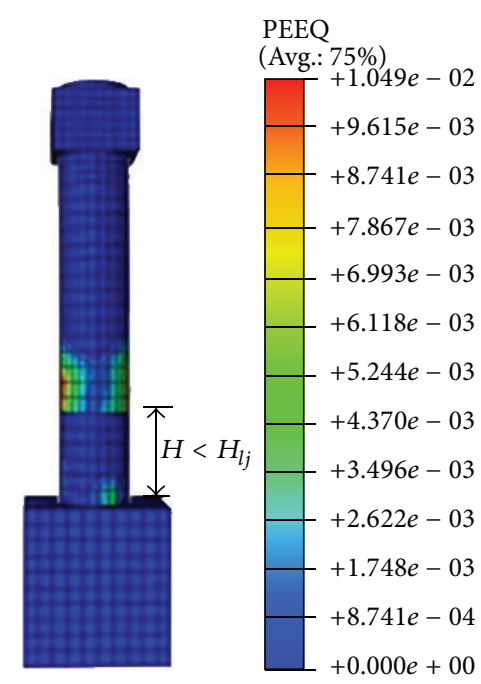

(a) $H=0.23 \mathrm{~L}$

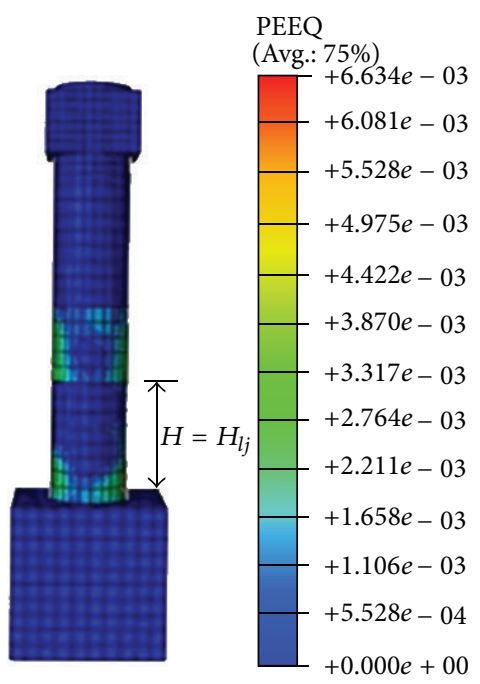

(b) $H_{l j}=0.3 \mathrm{~L}$

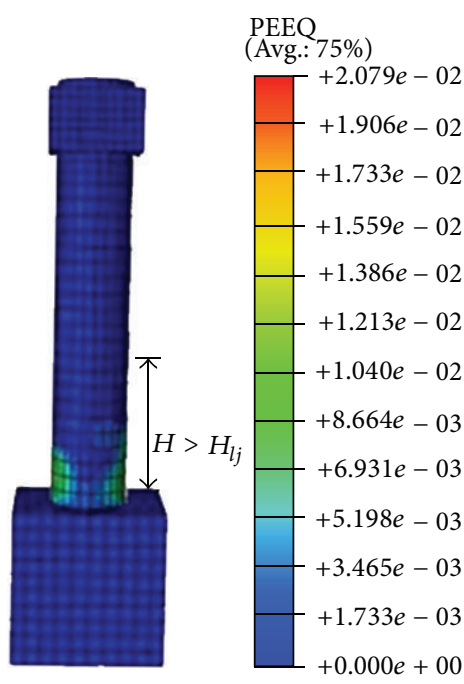

(c) $H=0.38 \mathrm{~L}$

FIGURE 17: Critical deteriorated segment height.

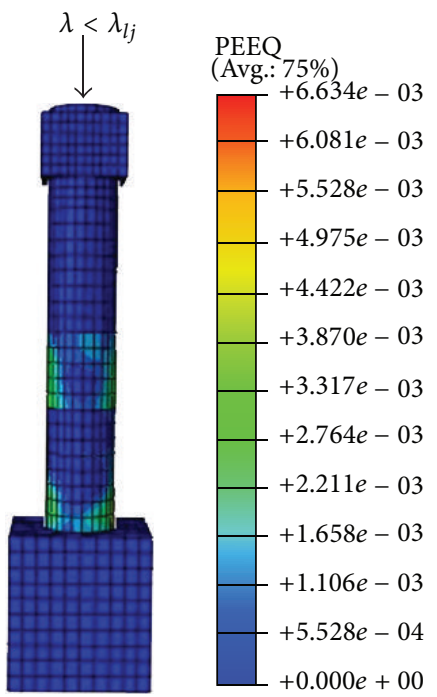

(a) $\lambda=0.2$
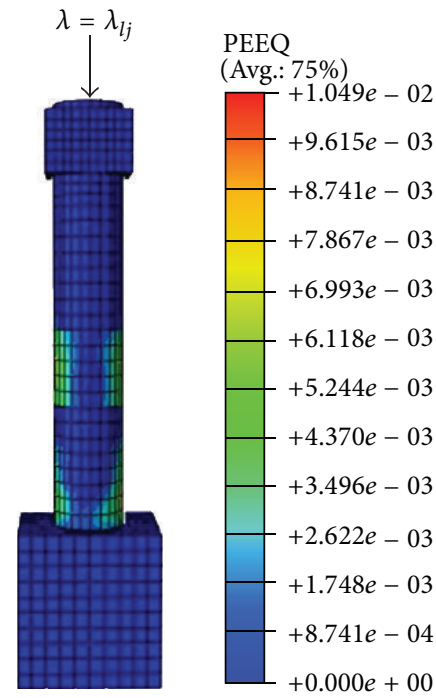

(b) $\lambda_{l j}=0.4$

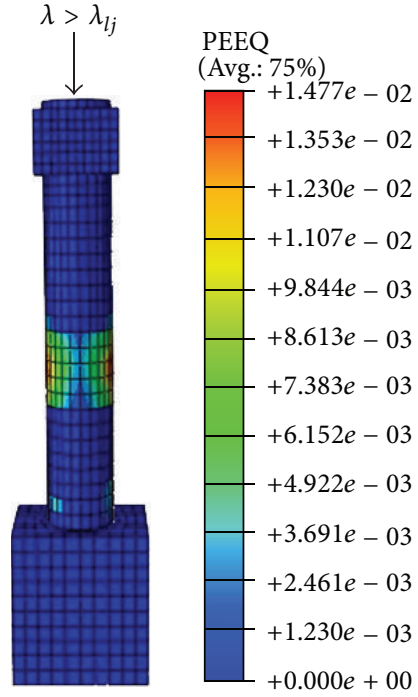

(c) $\lambda=0.6$

Figure 18: Effect of axial load ratio on critical deteriorated segment height.

were predicted with the numerical model mentioned above. Figure 22 indicates that the wrapping CFRP has significant effect on improving the seismic behaviors of partially deteriorated RC columns. When the specimen retrofitted with 1 layer to 4 layers of CFRP, the bearing capacity is $34.5 \mathrm{kN}, 37.4 \mathrm{kN}$, $39.7 \mathrm{kN}$, and $40.5 \mathrm{kN}$, respectively. The bearing capacity increases by $10.8 \%, 19.8 \%, 27.2 \%$, and $29.8 \%$ in comparison to the ones of unretrofitted deteriorated column BR200f, which means the effect of each layer CFRP on improving bearing capacity is decreasing with the increment of CFRP thickness. Thus, there is an upper limit to the thickness of CFRP in retrofitting RC columns. According to analytical results in Figure 22 and GB50367-2006 [22], 3 layers of CFRP are considered as the maximum effective thickness of CFRP in retrofitting engineering.

5.2. Influence Factors on Recoverability of Wrapped CFRP. The seismic behaviors of partially deteriorated RC column can be recovered by the wrapped CFRP, which has been verified by current experiment. Many factors affecting the recoverability are worth studying.

5.2.1. Axial Load Ratio. As shown in Figure 23, the hysteretic loops of control columns and their responding CFRP retrofitted deteriorated columns with three axial load ratios 


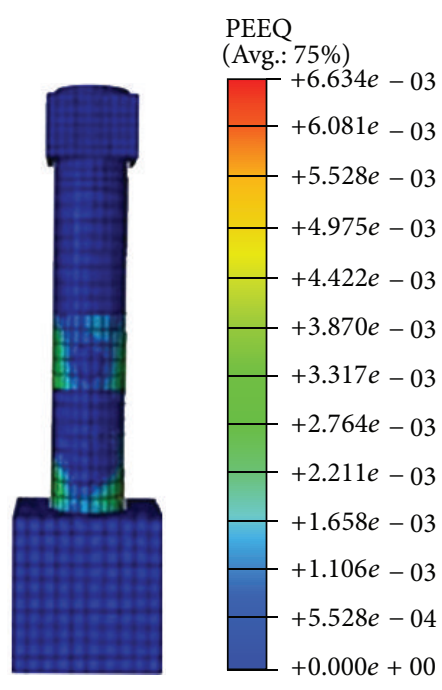

(a) $L / D=5.2$

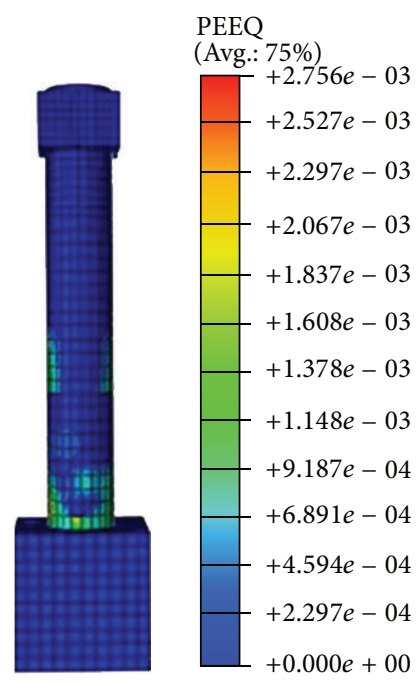

(b) $L / D=6$

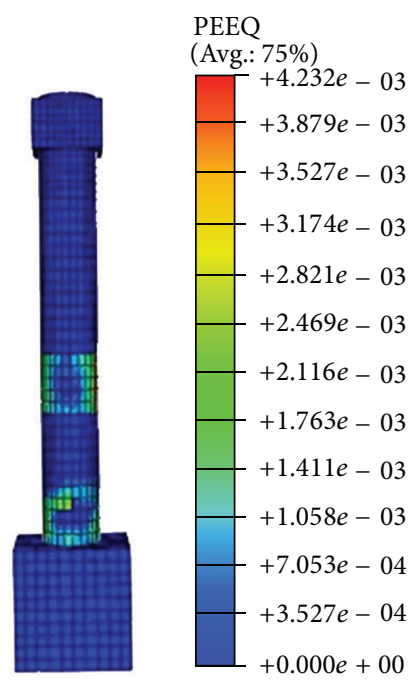

(c) $L / D=7$

FIGURE 19: Effect of slenderness ratio on critical deteriorated segment height.
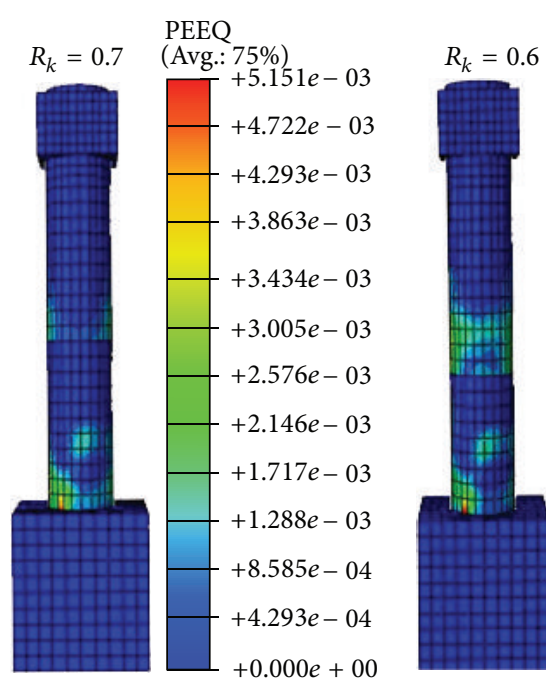

PEEQ

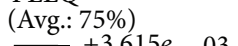

$+3.615 e-03$
$+3.314 e-03$

$+3.012 e-03$

$+2.711 e-03$

$+2.410 e-03$
$+2.109 e-03$

$+1.807 e-03$

$+1.506 e-03$

$+1.205 e-03$
$+9.037 e-04$

$+6.025 e-04$

$+3.012 e-04$

$+0.000 e+00$

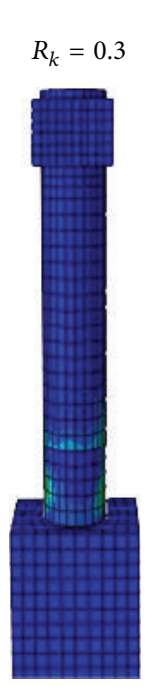

PEEQ

(Avg.: 75\%)

$+7.084 e-03$

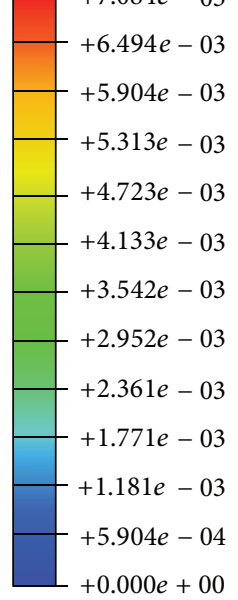

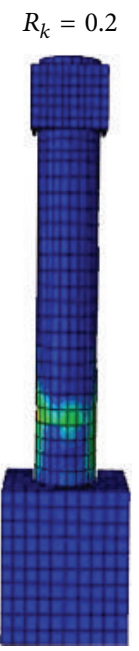

PEEQ

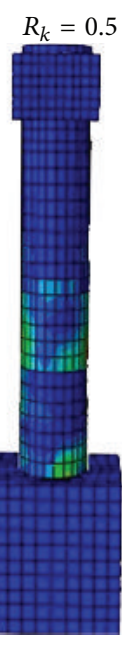

PEEQ

(Avg.: 75\%)

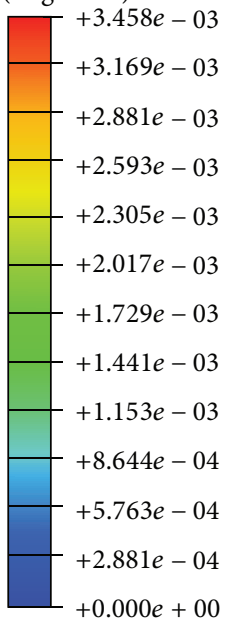

(Avg.: 75\%)

$+5.045 e-03$

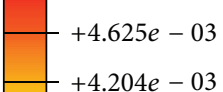

$+3.784 e-03$

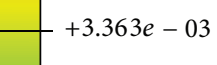

$+2.943 e-03$

$+2.523 e-03$

$+2.102 e-03$

$+1.682 e-03$
$+1.261 e-03$

$+8.409 e-04$

$+4.204 e-04$

$+0.000 e+00$
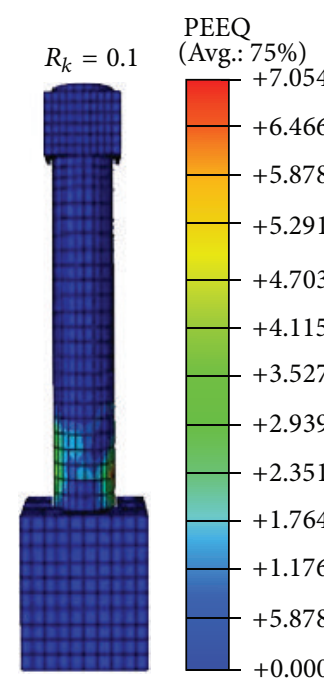

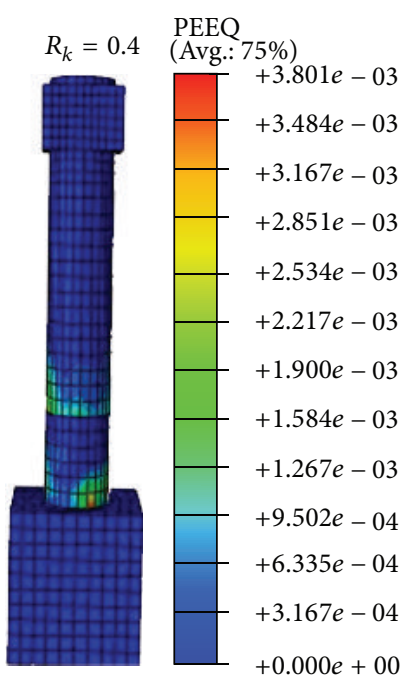

PEEQ
(Avg: $75 \%)$

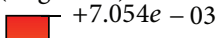

$[+7.054 e-03$

$+5.878 e-03$

$+5.291 e-03$

$+4.703 e-03$
$+4.115 e-03$

$+4.115 e-03$
$+3.527 e-03$

$+2.939 e-03$

$+2.351 e-03$

$+1.764 e-03$
$+1.176 e-03$

$+5.878 e-04$

FIGURE 20: Effect of deteriorated ratio on critical deteriorated segment height. 
TABLE 3: Critical deteriorated segment height of columns.

\begin{tabular}{lcccccc}
\hline$R_{k}$ & & \multicolumn{3}{c}{$P /\left(f_{w} \mathrm{~A}\right)$} & 0.35 & 0.45 \\
\hline 0.1 & 0.15 & 0.2 & 0.3 & 0.067 & 0.069 & 0.074 \\
0.2 & 0.057 & 0.058 & 0.060 & 0.138 & 0.138 \\
0.3 & 0.107 & 0.111 & 0.120 & 0.191 & 0.191 & 0.208 \\
0.4 & 0.163 & 0.165 & 0.176 & 0.246 & 0.246 & 0.269 \\
0.5 & 0.213 & 0.221 & 0.231 & 0.307 & 0.334 \\
0.6 & 0.269 & 0.273 & 0.292 & 0.389 & 0.389 \\
0.7 & 0.338 & 0.352 & 0.367 & 0.461 & 0.415 \\
\hline
\end{tabular}

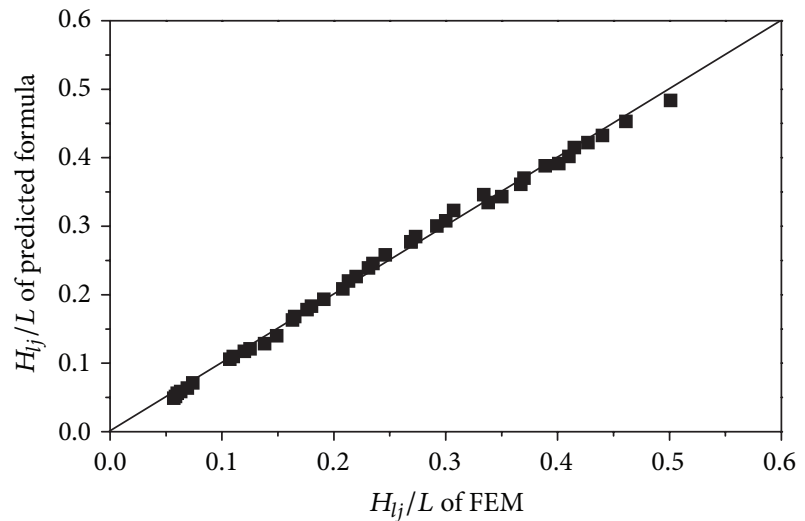

FIGURE 21: Diagram of critical deteriorated segment height of columns.

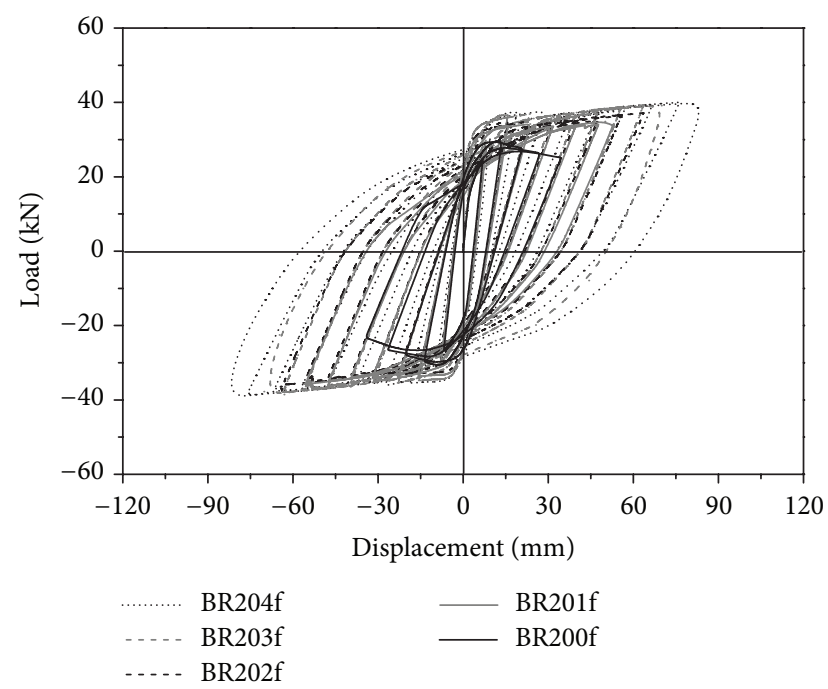

FIGURE 22: Numerical prediction of retrofitting effect of wrapping CFRP.

are predicted. Figure 23 shows that the bearing capacity of 3 layer retrofitted columns under different axial load ratios is different. With the increment of the axial load, the bearing capacity of 3-layer retrofitted columns is increasing before the axial load equal to 0.3 but decreasing after the value.

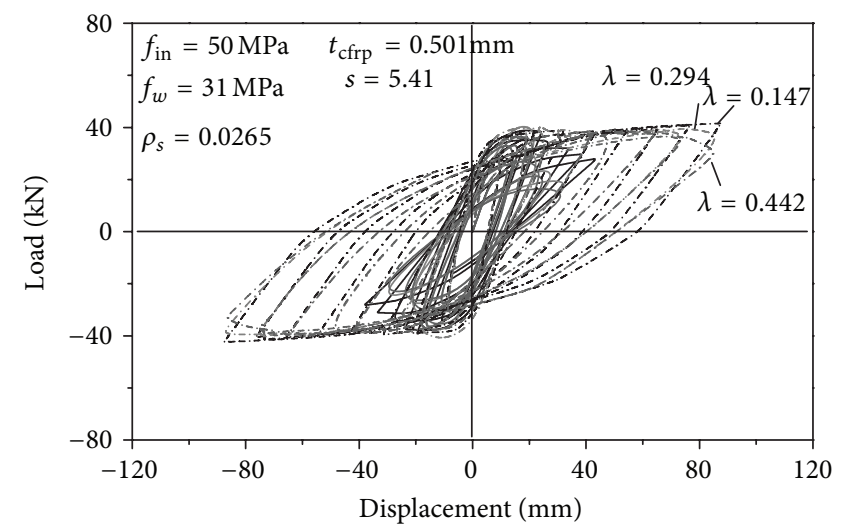

FIGURE 23: Hysteretic loops of numerical specimens with different axial load ratio.

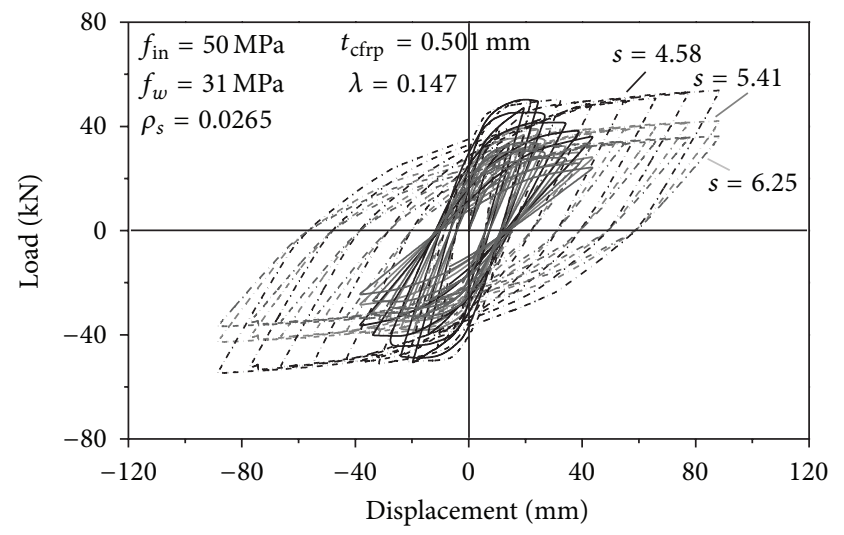

FIgURE 24: Hysteretic loops of numerical specimens with different slenderness ratio.

A similar regulation also exists in control columns. If the bearing capacity of a partially deteriorated column reaches the bearing capacity of control column by means of wrapping CFRP, the current thickness of CFRP is determined as the effective thickness to the partially deteriorated column, regardless of the axial load ratio. In other words, the axial load is insensitive to the recoverability of the wrapped CFRP on the partially deteriorated column.

5.2.2. Slenderness Ratio. Figure 24 is the hysteretic loops of control columns and retrofitted column with three different 


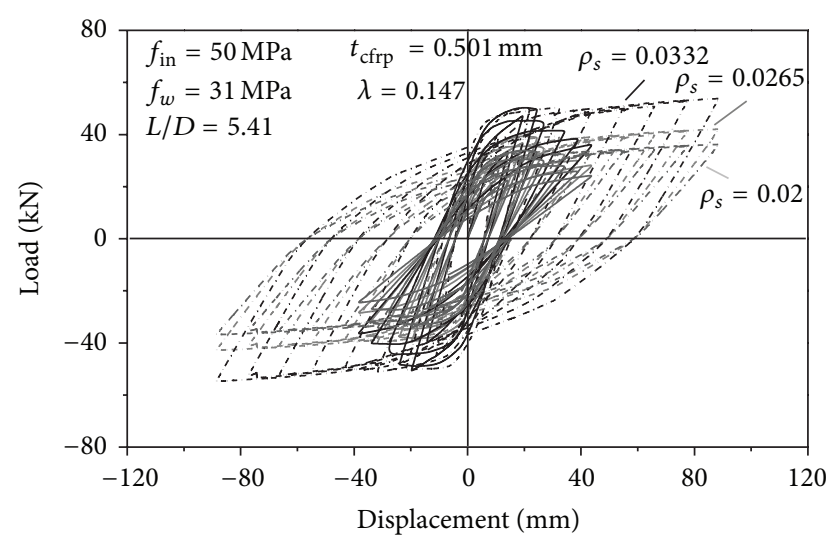

FIGURE 25: Hysteretic loops of numerical specimens with different reinforcement ratio.

slenderness ratios. The concrete strength of control columns examined in Figure 24 is $50 \mathrm{MPa}$. The deteriorated concrete strength of partially deteriorated column is $31 \mathrm{MPa}$, and the intact concrete strength is $50 \mathrm{MPa}$. The reinforcement ratio of the column in Figure 24 is 0.0265 , and the axial load of them, corresponding to the deteriorated strength, is 0.147 . Three slenderness ratios, $4.58,5.41$, and 6.25 , are selected to study the influence of slenderness ratio on the recoverability of 3-layer CFRP confinement. It is clearly seen that the bearing capacity of control columns and retrofitted columns decreases with increasing of the slenderness ratio. Thus, the slenderness ratio has little influence on the recoverability of wrapped CFRP.

5.2.3. Reinforcement Ratio. The influence of reinforcement ratio on the recoverability of wrapped CFRP is investigated, finally. As shown in Figure 25, the intact strength and deteriorated strength of columns studied in Figure 14 are $50 \mathrm{MPa}$ and $31 \mathrm{MPa}$, respectively. The slenderness ratio and axial load ratio are 5.41 and 0.147 , respectively. Partially deteriorated columns are retrofitted with 3-layer CFRP. Three reinforcement ratios $0.0332,0.0265$, and 0.02 are selected to study the influence of reinforcement ratio on the recoverability of wrapped CFRP. It is clearly visible that the bearing capacity of columns is increasing with the increment of the reinforcement ratio, regardless of the control columns and the retrofitted columns. Therefore, the reinforcement ratio has little relationship to the recoverability of wrapped CFRP.

5.3. Effective Confinement of CFRP. All the important parameters, reinforcement ratio, axial load ratio, and slenderness ratio, can influence the retrofitting effect and bearing capacity upgrading. However, the mentioned three parameters have little influence on the recoverability of wrapped CFRP to recover the seismic behaviors of partially deteriorated columns. Thus, the equivalent strength of retrofitted column can be determined as the target strength of deteriorated concrete in partially deteriorated column retrofitted with 3-layer CFRP. As shown in Figure 26, the confinement of 3-layer CFRP improves the bearing capacity of partially

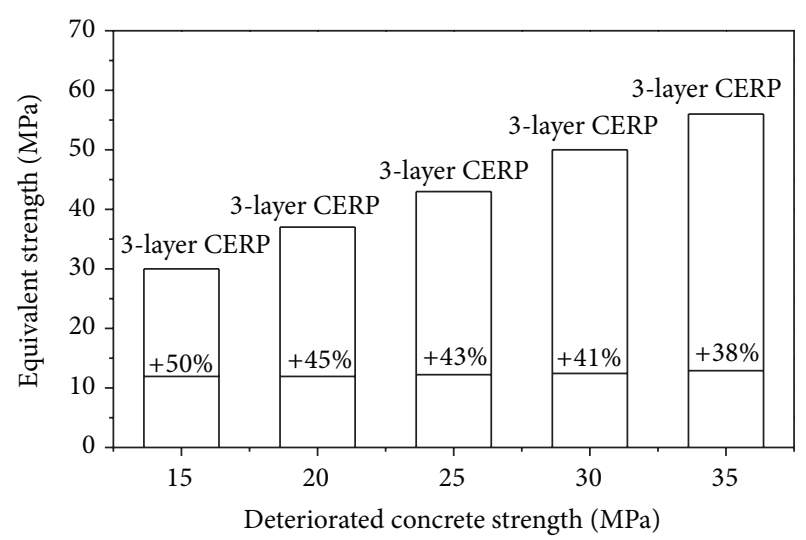

FIGURE 26: Equivalent strength of 3-layer CFRP retrofitted column.

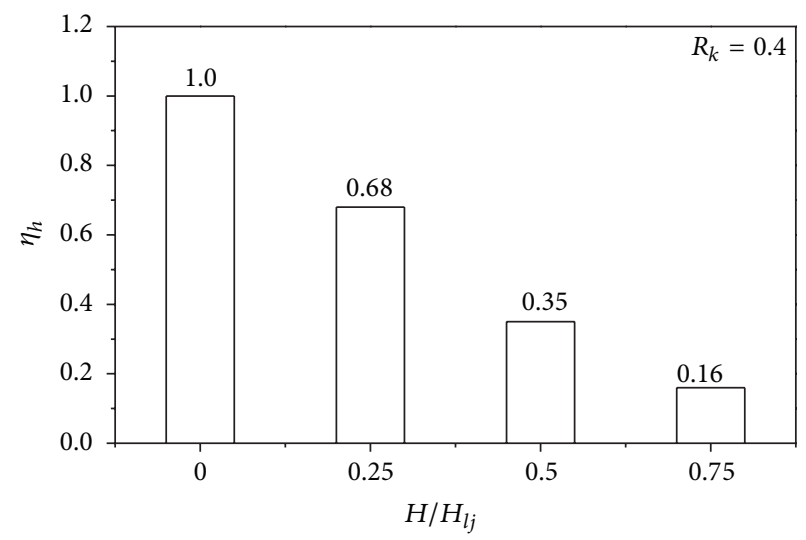

FIGURE 27: Discount index of deteriorated concrete location.

deteriorated column with different deteriorated concrete strength to varying degrees. When the deteriorated concrete strength is $15 \mathrm{MPa}$, the equivalent strength increases by $50 \%$, comparing to the deteriorated concrete strength, but when the deteriorated concrete strength is $35 \mathrm{MPa}$, the increment of bearing capacity decreases to $38 \%$. The confinement effect decreases with the increasing of deteriorated concrete strength. According to the pattern mentioned above, when the deteriorated concrete located at the plastic hinge zone of columns, the effectiveness of wrapped CFRP on recovering the seismic bearing capacity can be determined.

\subsection{Discount Index of Required CFRP Thickness}

5.4.1. Discount of Deteriorated Concrete Location. According to the research mentioned above, when the partially deteriorated concrete located at the plastic hinge zone, if the deteriorated ratio of partially deteriorated column is lower than the critical deteriorated ratio, wrapping 3-layer CFRP is effective to recover the seismic bearing capacity of partially deteriorated column. However, when the deteriorated concrete does not locate at the plastic hinge zone, 3 layers of CFRP are unnecessary. Figure 27 is the numerical result of required CFRP thickness of partially deteriorated columns with different deteriorated concrete location. As shown in 


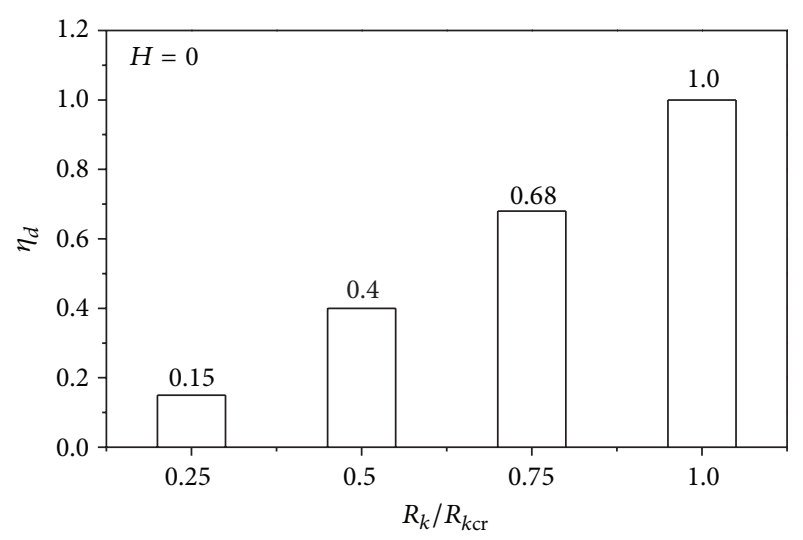

FIgURE 28: Discount index of deteriorated ratio.

Figure 27, the deteriorated ratio $R_{k}$ is 0.4 , and the discount index $\eta_{h}$ is decreased with the increasing of $H / H_{l j}$. When the value of $H / H_{l j}$ is equal to $0, \eta_{h}=1$, which means the deteriorated concrete locates at the plastic hinge zone, 3-layer CFRP is necessary. When the value of $H$ is close to $H_{l j}$, the $\eta_{h}$ tends to 0 , which means the reinforcement is unnecessary.

5.4.2. Discount of Deteriorated Ratio. As mentioned above, the required thickness of CFRP is related to not only the location of deteriorated concrete but also the deteriorated ratio of partially deteriorated column. If the deteriorated ratio is lower than the critical deteriorated ratio of partially deteriorated column, 3-layer CFRP retrofitting is also unnecessary. The numerical results of CFRP thickness discount are shown in Figure 28, in which the deteriorated concrete is located at the plastic hinge zone $(H=0)$. The discount index of deteriorated ratio $\eta_{d}$ increases with the increasing of the value of $R_{k} / R_{\mathrm{kcr}}$. $R_{\mathrm{kcr}}$ is defined as the critical deteriorated ratio. The value of $R_{k} / R_{\mathrm{kcr}}$ equaling 1 means that the deteriorated ratio is equal to the critical deteriorated ratio, $\eta_{d}=1$, no discount needed. The value of $R_{k} / R_{\mathrm{kcr}}$ tends to 0 which means the column is an intact column, $\eta_{d}$ tends to 0 , and retrofitting with CFRP is unnecessary.

It is concluded from the research above that the maximum effective thickness of wrapped CFRP $t_{\max }$ is 3 layers $(0.501 \mathrm{~mm})$ and discount of deteriorated ratio and deteriorated concrete location should be considered when the appropriate thickness of wrapped CFRP is calculated. The required thickness of wrapped CFRP $t_{\text {req }}$ can be determined as in the following equation:

$$
t_{\text {req }}=\eta_{h} \cdot \eta_{d} \cdot t_{\max } \cdot
$$

\section{Conclusion}

According to the researches above, the following conclusions are obtained.

(1) 3D finite element model of ABAQUS/Standard can accurately predict the hysteretic loops and failure locations of partially deteriorated columns and the effect of wrapped CFRP. When the partial deterioration of concrete located at the plastic hinge zone, the deteriorated concrete could weaken the seismic behaviors of RC columns. The bearing capacity can be mostly recovered by the confinement of wrapped CFRP.

(2) The risk of the partially deteriorated concrete to the column is related to the deteriorated ratio, the location of deteriorated segment, and the axial load ratio of RC column. When the location of deterioration $H<H_{l j}$, partial deterioration could weaken the seismic behaviors of RC columns, and retrofitting is necessary to recover the seismic behaviors of columns. Otherwise, the partial deterioration has little effect on the seismic behaviors of columns. The proposed equation (2) can be used for risk assessment of partially deteriorated segment on column.

(3) Wrapping CFRP sheets is effective to recover the seismic behaviors of partially deteriorated columns. Three-layer CFRP is considered as the maximum effective thickness of CFRP. CFRP retrofitting method is effective to the partially deteriorated column whose deteriorated ratio is less than 0.5 . The discount related to the deteriorated ratio and deteriorated concrete location should be considered by the discount index. The required thickness of CFRP can be determined by (3) to make retrofitting scheme with CFRP.

\section{Conflict of Interests}

The authors declare that there is no conflict of interests regarding the publication of this paper.

\section{Acknowledgments}

The financial support from the National Natural Science Foundation with Grant nos. 50578025 and 51121005 and the National Basic Research Program (973 Program) with Grant no. 2009CB623200, China, is greatly acknowledged.

\section{References}

[1] G. Promis and E. Ferrier, "Performance indices to assess the efficiency of external FRP retrofitting of reinforced concrete short columns for seismic strengthening," Construction and Building Materials, vol. 26, no. 1, pp. 32-40, 2012.

[2] G. Promis, E. Ferrier, and P. Hamelin, "Effect of external FRP retrofitting on reinforced concrete short columns for seismic strengthening," Composite Structures, vol. 88, no. 3, pp. 367-379, 2009.

[3] F. Colomb, H. Tobbi, E. Ferrier, and P. Hamelin, "Seismic retrofit of reinforced concrete short columns by CFRP materials," Composite Structures, vol. 82, no. 4, pp. 475-487, 2008.

[4] L. P. Ye, K. Zhang, S. H. Zhao, and P. Feng, "Experimental study on seismic strengthening of RC columns with wrapped CFRP sheets," Construction and Building Materials, vol. 17, no. 6-7, pp. 499-506, 2003. 
[5] A. Shamim and Y. Grace, "Seismic behavior of concrete columns confined with steel and fiber-reinforced polymers," ACI Structural Journal, vol. 99, no. 1, pp. 72-80, 2002.

[6] S. A. Sheikh and O. Bayrak, "Seismic behaviour of FRPretrofitted concrete columns," in Proceedings of the Structural Congress and Exposition, pp. 1-8, Washington, DC, USA, May 2001.

[7] R. D. Iacobucci, S. A. Sheikh, and O. Bayrak, "Retrofit of square concrete columns with carbon fiber-reinforced polymer for seismic resistance," ACI Structural Journal, vol. 100, no. 6, pp. 785-794, 2003.

[8] H. Wei, Z. Wu, X. Guo, and F. Yi, "Experimental study on partially deteriorated strength concrete columns confined with CFRP," Engineering Structures, vol. 31, no. 10, pp. 2495-2505, 2009.

[9] H. Wei, Z. Wu, and P. Zhang, "Axial experiment on CFRP confined steel reinforced concrete columns with partial deteriorated strength," Journal of Reinforced Plastics and Composites, vol. 29, no. 6, pp. 874-882, 2010.

[10] H. Wei, Compressive Performance Study on CFRP Wrapped Concrete Columns with Partial Deteriorated Strength, Dalian University of Technology, Dalian, China, 2009.

[11] ABAQUS Standard User's Manual (Version 6.8-1), Hibbitt \& Karlsson, 2008.

[12] Y. Goto, G. P. Kumar, and N. Kawanishi, "Nonlinear finiteelement analysis for hysteretic behavior of thin-walled circular steel columns with in-filled concrete," Journal of Structural Engineering, vol. 136, no. 11, pp. 1413-1422, 2010.

[13] J. Lubliner, J. Oliver, S. Oller, and E. Oñate, "A plastic-damage model for concrete," International Journal of Solids and Structures, vol. 25, no. 3, pp. 299-326, 1989.

[14] J. Lee and G. L. Fenves, "Plastic-damage model for cyclic loading of concrete structures," Journal of Engineering Mechanics, vol. 124, no. 8, pp. 892-900, 1998.

[15] J. Wang, Application of ABAQUS in Civil Engineering, Press of Zhejiang University, Zhejiang, China, 2006.

[16] M. M. Attard and S. Setunge, "Stress-strain relationship of confined and unconfined concrete," ACI Materials Journal, vol. 93, no. 5, pp. 432-441, 1996.

[17] "ACI building code requirements for structural concrete and commentary," Tech. Rep. ACI 318M-08, American Concrete Institute, Farmington Hills, Mich, USA, 2008.

[18] P. Mark and V. Birtel, "Parameterized finite element modeling of RC beam shear failure," in Proceeding of the ABAQUS User's Conference, pp. 95-108, Bochum, German, 2006.

[19] CEB-FIB model code 2010. Switzerland : International Federation for Structural Concrete; 2010.

[20] V. Gopalaratnam and S. Shah, "Softening response of plain concrete in direct tension," ACI Materials Journal, vol. 12, no. 5-6, pp. 310-323, 1985.

[21] J. G. Teng, T. Jiang, L. Lam, and Y. Z. Luo, "Refinement of a design-oriented stress-strain model for FRP-confined concrete," Journal of Composites for Construction, vol. 13, no. 4, pp. 269278, 2009.

[22] Design Code for Strengthening Concrete Structure. GB503672006, Ministry of Construction of P. R. China, Beijing, China, 2006. 


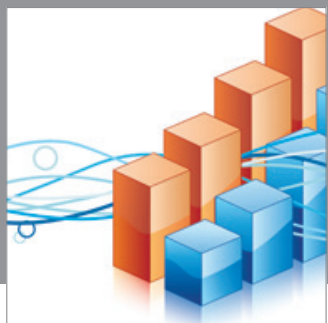

Advances in

Operations Research

mansans

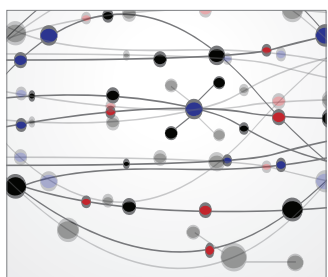

The Scientific World Journal
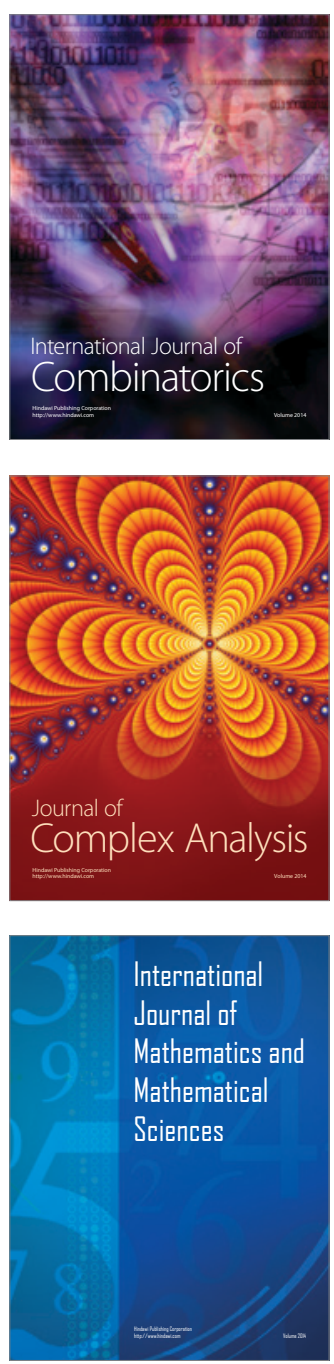
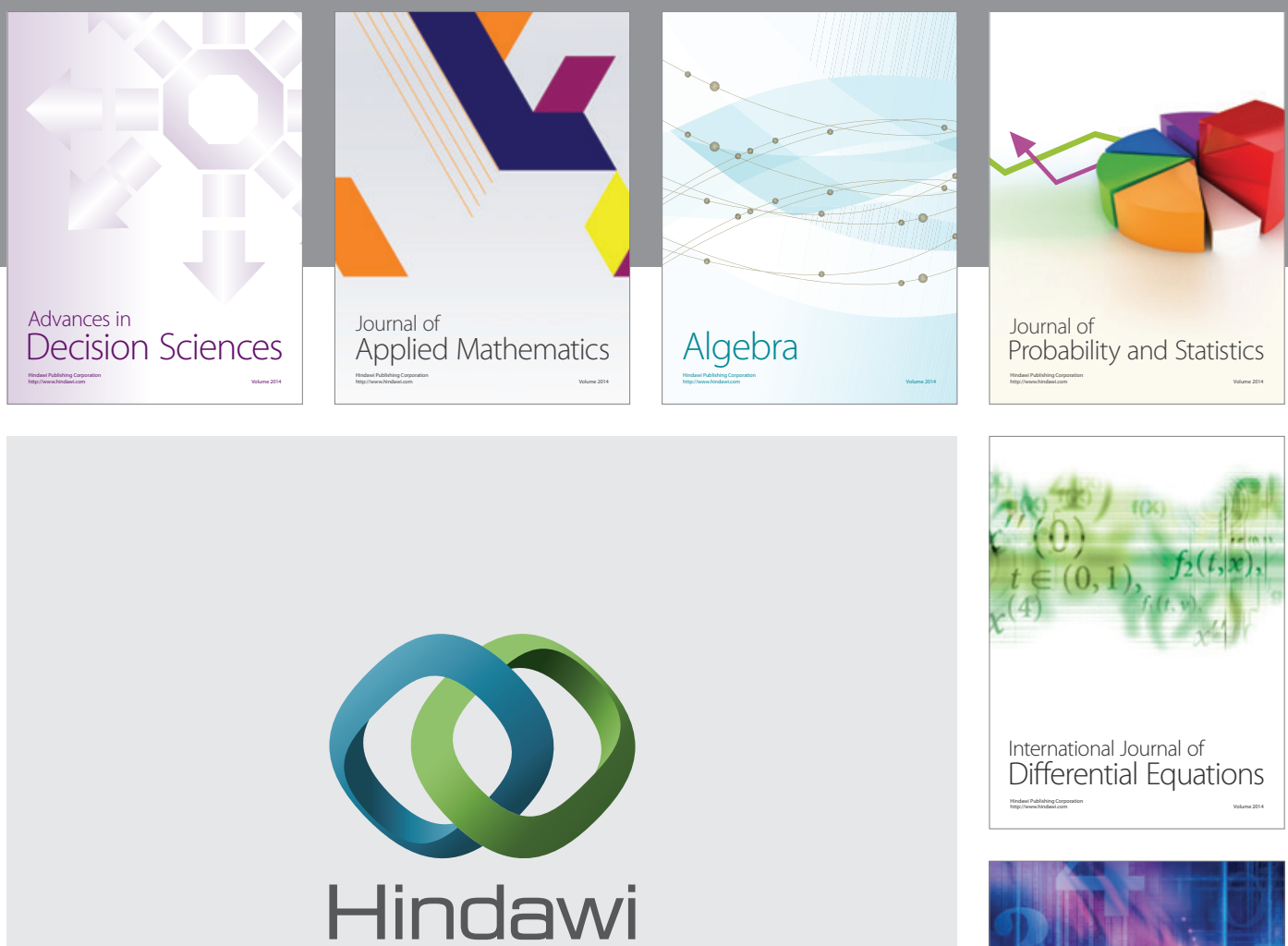

Submit your manuscripts at http://www.hindawi.com
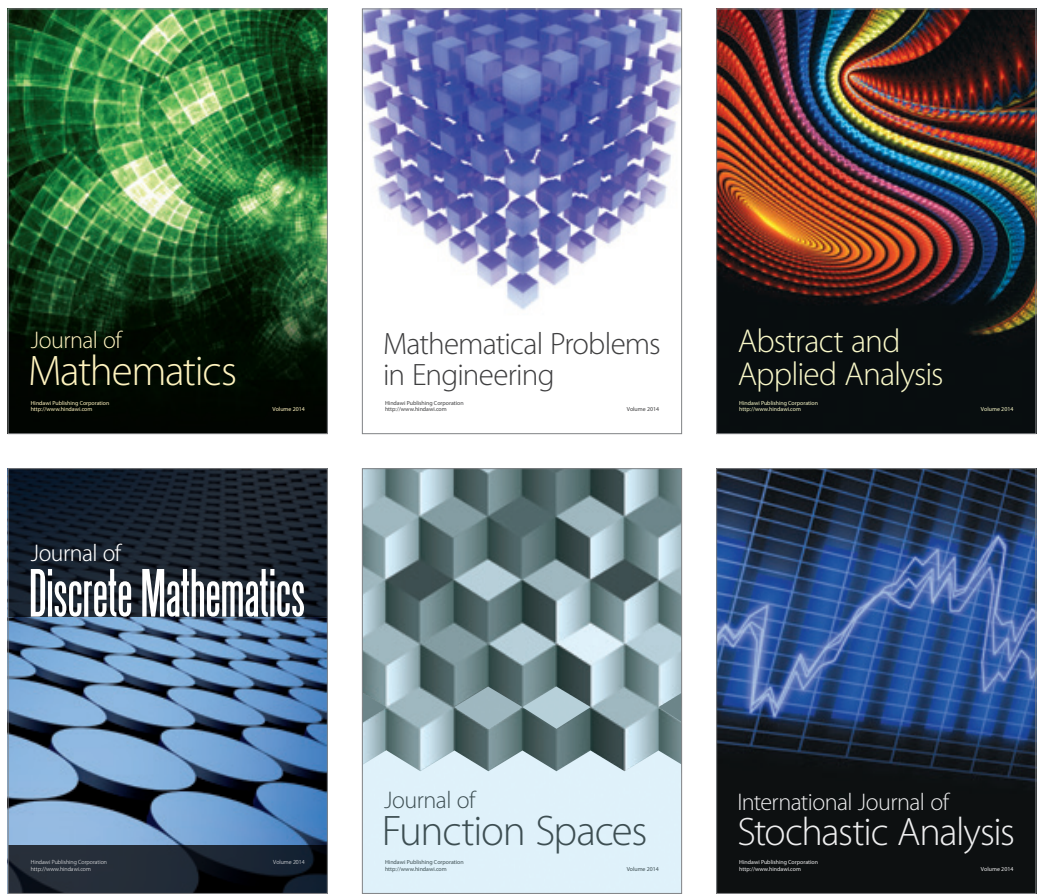

Journal of

Function Spaces

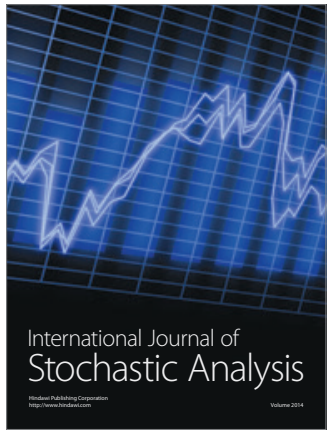

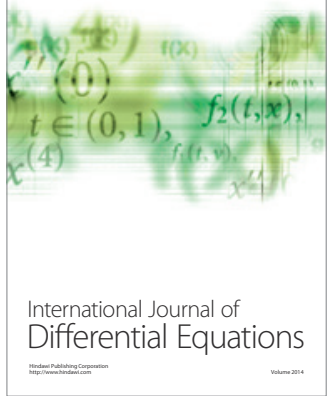
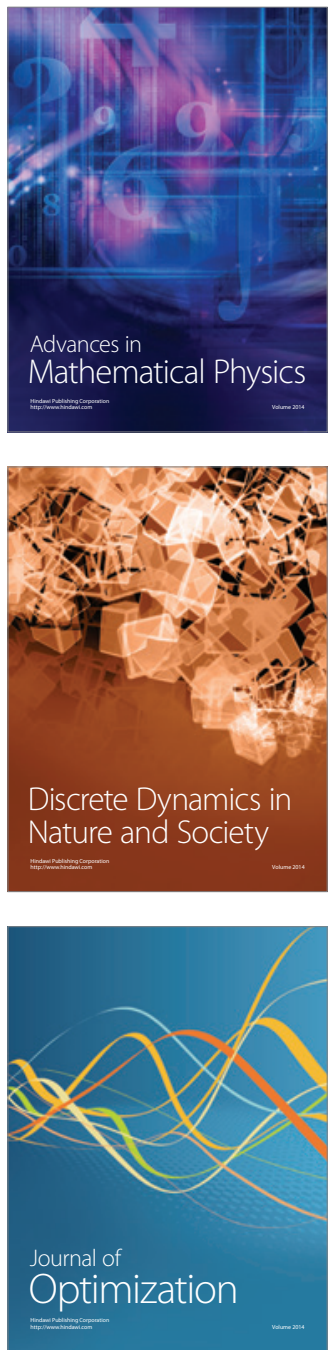